
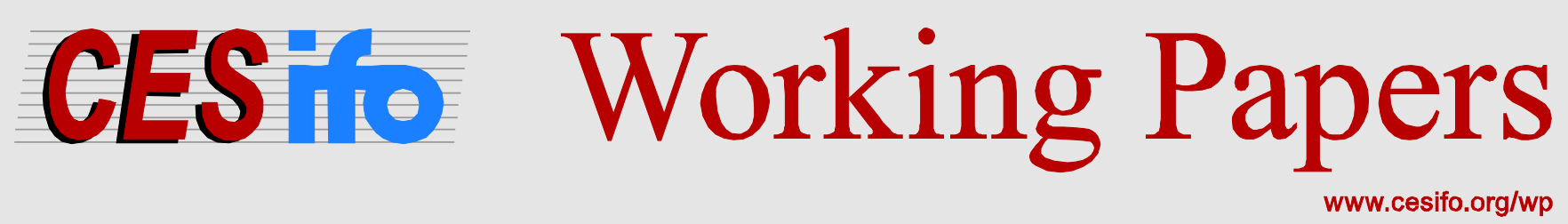

\title{
Agricultural Trade, Biodiversity Effects and Food Price Volatility
}

\author{
Cecilia Bellora \\ Jean-Marc Bourgeon
}

\begin{abstract}
CESIFO WORKING PAPER NO. 5417
CATEGORY 9: RESOURCE AND ENVIRONMENT ECONOMICS

JUNE 2015

Presented at CESifo Area Conference on Applied Microeconomics, March 2015

An electronic version of the paper may be downloaded

- from the SSRN website:

- from the RePEc website:

- from the CESifo website:

wWw.SSRN.com

www.RePEc.org

www.CESifo-group.org/wp
\end{abstract}




\title{
Agricultural Trade, Biodiversity Effects and Food Price Volatility
}

\begin{abstract}
Biotic factors such as pests create biodiversity effects that increase production risks and decrease land productivity when agriculture becomes more specialized. We show in a Ricardian two-country trade setup that production specialization is incomplete under free trade because of the decrease in land productivity. Pesticides allow farmers to reduce these biodiversity effects, but they are damaging for the environment and for human health. When regulating farming practices under free trade, governments face a trade-off: they are tempted to restrict pesticide use compared to under autarky because domestic consumption partly relies on imports and thus depends less on them, but they also want to preserve the competitiveness of their agricultural sector on international markets. We show that at the symmetric equilibrium under free trade, restrictions on pesticides are generally more stringent than under autarky. As a result, trade increases the price volatility of crops produced by both countries, and of some or all of the crops that are country-specific, depending on the intensity of the biodiversity effects.
\end{abstract}

JEL-Code: F180, Q170.

Keywords: agricultural trade, food prices, agrobiodiversity, pesticides.

\author{
Cecilia Bellora \\ CEPII \\ 113 rue de Grenelle \\ France - 75007 Paris \\ cecilia.bellora@cepii.fr
}

\author{
Jean-Marc Bourgeon \\ UMR Économie publique \\ AgroParisTech-Paris \\ 16, rue Claude Bernard \\ France- 75231 Paris Cedex 05 \\ bourgeon@agroparistech.fr
}

June, 2015

The authors are grateful to Brian Copeland for his comments and suggestions. They also thank seminar participants at Ecole Polytechnique, at the 2014 BioEcon conference, at the 2014 conference of the French Association of Environmental and Resource Economists, and at the 2015 CESifo Area Conference on applied microeconomics. The research leading to these results has received funding from the European Union's Seventh Framework Programme FP7/2007-2001 under Grant Agreement 290693 FOODSECURE. The authors only are responsible for any omissions or deficiencies. Neither the FOODSECURE project and any of its partner organizations, nor any organization of the European Union are accountable for the content of this paper. Much of this work was done while Cecilia Bellora was a PhD student at Université de Cergy-Pontoise and INRA. 


\section{Introduction}

Agricultural prices are historically more volatile than manufacture prices (Jacks et al., 2011). Perhaps because this stochasticity is considered to be due to factors beyond human control, such as weather conditions, economic studies analyzing agricultural price volatility focus mainly on factors related to market organization, such as demand variability and the role played by stocks. ${ }^{1}$ However, in addition to abiotic factors, such as water stress, temperature, irradiance and nutrient supply, which are often related to weather conditions, production stochasticity is also caused by biotic factors, also known as "pests" - including animal pests (such as insects, rodents, birds, etc.), pathogens (such as viruses, bacteria, fungi, etc.), or weeds - which are harmful organisms that can cause critical harvest losses. ${ }^{2}$ The impact of pests on yields is linked to the degree of specialization of the agricultural sector, which depends on the country's openness to trade. The more cultivation is concentrated on a few high-yielding crops, the more pests specialize on these crops and the greater their virulence. Yields become more variable with specialization and the probability of low harvests rises. This variability is very much reduced by the use of agrochemicals (pesticides, fungicides, herbicides and the like). ${ }^{3}$ But these chemicals generate negative externalities, on human health, biodiversity, water and air quality. ${ }^{4}$ Trade questions the necessity of using pesticides because of NIMBY (Not in My Back Yard) considerations: some of the food consumed locally is produced abroad, therefore eliminating the amount of pesticide that would have been needed to grow it at home. Moreover, the portion of the food grown locally that is sold abroad exposes

\footnotetext{
${ }^{1}$ See Gilbert \& Morgan (2010) and Wright (2011) for overviews on food price volatility and examinations of the causes of recent price spikes.

${ }^{2}$ According to Oerke (2006), potential losses due to pests (i.e. without crop protection of any kind) between 2001 and 2003 were $50 \%$ for wheat, $77 \%$ for rice and $80 \%$ for cotton, among others. Savary et al. (2000) also find significant losses: the combined average level of injuries led to a decrease of $37.2 \%$ in rice yield (if injuries were considered individually, the cumulative yield loss would have been $63.4 \%$ ). Fernandez-Cornejo et al. (1998) compile similar data on previous periods and find that expected losses from insects and diseases relative to current or potential yield range between 2 to $26 \%$ and that losses from weeds range between $0 \%$ and $50 \%$.

${ }^{3}$ In the case of wheat, they reduce potential losses of $50 \%$ to average actual losses of about $29 \%$ (from $14 \%$ in Northwest Europe up to $35 \%$ and more in Central Africa and Southeast Asia). Actual losses for soybean average around $26 \%$. The order of magnitude of losses for maize and rice is greater, with actual losses of respectively $40 \%$ and $37 \%$ (Oerke, 2006).

${ }^{4}$ Pimentel (2005) reports more than 26 million cases worldwide of non-fatal pesticide poisoning and approximately 220,000 fatalities. He estimates that the effects of pesticides on human health cost about 1.2 billion US $\$$ per year in the United States. Mammals and birds are also affected. Farmland bird population decreased by 25\% in France between 1989 and 2009 (Jiguet et al., 2012), and a sharp decline was also observed in the whole EU during the same period (EEA, 2010). Pesticides also contaminate water and soils and significantly affect water species both locally and regionally (Beketov et al., 2013). Many countries have adopted regulations that forbid the most harmful molecules, have set provisions on the use and storage of pesticides, and promote their sustainable use. For example, only a fourth of the previously marketed molecules passed the safety assessment made within the European review process ended in 2009 (EC, 2009). The use of pesticides seems to follow a decreasing trend: in Europe, quantities sold decreased by $24 \%$ between 2001 and 2010 (ECP, 2013).
} 
the local population to pesticide externalities without benefitting them personally. The government regulating farming practices under free trade is then faced with a trade-off: if it reduces pesticide use compared to the rate under autarky it can satisfy NIMBY concerns, but doing so will reduce the trade competitiveness of its agricultural sector, which depends on the intensive use of pesticides.

The aim of this paper is to formally analyze how crop biodiversity and environmental policies interact with trade, and to derive the role of biotic factors on price volatility. We develop a simple model of farm production affected by biotic factors that vary with specialization to represent the impacts of crop biodiversity on agricultural productivity and on the pattern of trade in a Ricardian two-country setup. We isolate these impacts by assuming that pesticide use is regulated by an environmental tax with no distributional effects, and we abstract from risk aversion by assuming that farmers and consumers are risk neutral. ${ }^{5}$

Our analysis provides three main findings. First, while countries have differing comparative advantage under autarky, biodiversity effects lead to incomplete specialization under free trade. Indeed, because specialization reduces the expected yield of crops, some of them are produced by both countries because their agricultural sectors end up with the same productivity given the intensity of cultivation at equilibrium. Second, the trade-off in the design of environmental policies results in restrictions on pesticides more stringent under free trade than under autarky: NIMBY considerations are prevalent over the market share rivalry that opposes the two countries. Third, agricultural price distributions depend on the pattern of trade. Trade increases the production volatility of crops produced by both countries. Country-specific crops for which comparative advantages are large could see a reduction in their volatility, but that supposes very small biodiversity effects. The expected market price of country-specific crops is increased for domestic consumers of the producing country compared to under autarky. This is becaused of more restrictive environmental policies and the intensification of production. For crops produced by both countries, the change in expected prices depends on the share of farmland devoted to these crops compared to under autarky.

Our work is related to different strains of literature. The link between crop biodiversity, yield and revenue variability is empirically investigated in Smale et al. (1998); Di Falco \& Perrings (2005); Di Falco \& Chavas (2006). These studies find sometimes contrasting results but generally tend to show that increasing agricultural biodiversity is associated with higher production and lower risk exposure (Di Falco, 2012). We add to this literature an economic foundation of the mechanisms at stake. ${ }^{6}$ We build on Weitzman (2000) to

\footnotetext{
${ }^{5}$ Risk aversion would lead the government to reduce specialisation under trade to diversify production risks among countries, as demonstrated by Gaisford \& Ivus (2014).

${ }^{6}$ For more details on the biological mechanisms involved, see Tilman et al. (2005), who use simple ecological models to describe the positive influence of diversity in the biomass produced and corroborate their findings with empirical results detailed in Tilman \& Downing (1994) and Tilman et al. (1996).
} 
model farm production with biodiversity effects: the larger the share of farmland dedicated to a crop, the more its parasitic species proliferates and thus the more fields of that crop are at risk of being wiped out. ${ }^{7}$ Weitzman (2000) uses this model to solve the trade-off between the private and social optima, the former tending to specializing on a few varieties while the latter aims at preserving biodiversity. We depart from his work by considering a trade context, incorporating the use of pesticides, and investigating the impact of biodiversity effects on production and price distributions. Our setup is a Ricardian trade model with two countries and many goods, à la Dornbusch et al. (1977). The incorporation of uncertainty in trade models dates back to Turnovsky (1974), who analyzes how the pattern of trade and the gains from trade are affected by uncertainty. Newbery \& Stiglitz (1984) analyze how the production choices of risk-averse farmers are affected under free trade when production is uncertain and show that free trade may be Pareto inferior to no trade. Then, a whole range of literature looks at the optimal trade policy in presence of risk aversion, one of the recent contributions being Gaisford \& Ivus (2014), who consider the link between protection and the size of the country. In these models, as well as in the recent Ricardian models involving more than two countries (Eaton \& Kortum, 2002; Costinot \& Donaldson, 2012), the stochastic component that affects production and determines the pattern of trade is not related to the production process itself. In that sense, it is "exogenous." We instead consider a stochastic component embedded in the production process and endogenously determined by the country's openness to trade: biotic and abiotic factors affect production stochastically, which generates price volatility, and also causes productivity losses that prevent complete specialization.

The rest of the paper is organized as follows: the next section details the relationship between crop biodiversity and the stochastic distribution of the agricultural production. We determine the profit-maximizing equilibrium of the agricultural sector and show that biodiversity effects result in an incomplete specialization under free trade. Section 3 is devoted to the environmental policy. Optimal environmental tax policies are derived with and without crop biodiversity effects, and in two situations: when governments ignore the terms of trade effects of the tax and when they take them into account. This allows us to disentangle the consequences of the different concerns that define the tax policy under trade, i.e. the NIMBY considerations and the market share rivalry. The implication of the interaction between biodiversity effects and environmental policies on agricultural price volatility is exposed in section 4 .

\footnotetext{
${ }^{7}$ Weitzman (2000) makes an analogy between parasite-host relationships and the species-area curve that originally applies to islands: the bigger the size of an island, the more species will be located there. He compares the total biomass of a uniform crop to an island in a sea of other biomass. A large literature in ecology uses the species-area curve which is empirically robust not only for islands but, more generally, for uniform regions (May, 2000; Garcia Martin \& Goldenfeld, 2006; Drakare et al., 2006; Plotkin et al., 2000; Storch et al., 2012).
} 


\section{The model}

To investigate the importance of biodiversity effects on the pattern of trade and on price volatility, we re-examine the standard Ricardian model of trade as developed by Dornbusch et al. (1977). Here, we consider two-sector economies, with an industrial/service sector which produces a homogeneous good (with equal productivities in the two countries and used as the numeraire) and an agricultural sector producing a range of goods with different potential yields. The effective yields depend on this potential yield but also on biotic and abiotic stochastic factors. They also depend on the use of pesticides, which is regulated by governments. The first part of this section details the farms' stochastic production setup and the resulting supply functions. Demands are derived in the second subsection. Then, we derive the autarky equilibrium. Although by assumption potential yields are different, in our simplified framework consumer preferences and the other characteristics of the two economies are such that the autarky case displays symmetric situations: the agricultural revenue, land rent and environmental tax are at the same levels in the two countries. Only crop prices differ since yields are different in the two countries.

\subsection{Production}

Consider two countries (Home and Foreign) whose economies are composed of two sectors; industry and agriculture. Our focus being on agriculture, the industrial/service sector is summarized by a constant return to scale production technology that allows to produce one item with one unit of labor. The industrial good serves as the numeraire which implies that the wage in these economies is equal to 1 . The agricultural sector produces a continuum of crops indexed by $z \in[0,1]$ using three factors: land, labor and agrochemicals (pesticides, herbicides, fungicides and the like) directed to control pests and dubbed "pesticides" in the following. ${ }^{8}$ Home is endowed with $L$ units of labor and $N$ land plots, and Foreign with $L^{*}$ and $N^{*}$ (asterisks are used throughout the paper to refer to the foreign country). As farming one plot requires one unit of labor, industry employs $L-N$ workers.

Technical coefficients in agriculture differ from one crop to the other, and from one country to the other. More precisely, absent production externality and adverse meteorological or biological events, this mere combination of one unit of labor with one unit of land produces $\bar{a}(z)$ crop $z$ in Home and $\bar{a}^{*}(z)$ in Foreign. Crops are ranked in order of diminishing Home's absolute yield: the relative crop yield $A(z) \equiv \bar{a}^{*}(z) / \bar{a}(z)$ satisfies $A^{\prime}(z)>0, A(0)<1$ and $A(1)>1$. Hence, on the basis of these differences in potential

\footnotetext{
${ }^{8}$ In order to streamline the analysis, we don't consider fertilizers. We discuss the way to incorporate them in our model in Appendix I.
} 
yield, Home is more efficient producing goods belonging to $\left[0, z_{s}\right)$ and Foreign over $\left(z_{s}, 1\right]$ where $z_{s}=A^{-1}(1)$.

However, production of crops is affected by various factors resulting in an actual yield that is stochastic and lower than the potential one. Factors impacting production are both abiotic and biotic, the impact of the latter depending on the way crops are produced: the more land that is dedicated to the same crop, the more pests specialize on this crop, the higher the frequency of their attacks and the lower the survival probability of that crop (Pianka, 2011). To counteract the impact of external events on her plot, a farmer can avail herself of a large range of chemicals, but because of the externality due to pesticides (on human health and the environment) governments restrict their use. To ease the exposition and simplify the following derivations, we model the governmental policy as a tax which results in a pesticide's price $\tau$, and we suppose that the governments complement this tax policy with a subsidy that allows farmers to cope with the environmental regulation: at equilibrium, it is financially neutral for farmers. We assume that farmers are risk-neutral and may farm only one crop (the one they want) on one unit plot. Given her crop choice, farmer $i$ chooses the intensity of the chemical treatment $\pi_{i}$ of her field in order to reach expected income

$$
r_{i}(z) \equiv \max _{\pi_{i}} \mathrm{E}\left[\tilde{p}(z) \tilde{y}_{i}(z)\right]-\tau \pi_{i}+T(z)-c
$$

where $\tilde{p}(z)$ is the stochastic crop $z$ price, $\tilde{y}_{i}(z)$ her stochastic production level, $T(z)$ the subsidy for crop $z$, which is considered as a lump sum payment to farmer $i$, and $c$ the other input costs, i.e. the sum of the wage (one unit of labor is necessary to farm a plot of land) and rental price of land, which is the same whatever crop is farmed. In the following, we assume that a unit plot is affected by one or several adverse conditions with probability $1-\psi$, independently of the fate of the other plots. If affected, its production is totally destroyed. Otherwise, with probability $\psi$, the plot survives and produces $\bar{a}(z) .^{9}$ The survival probability of a given crop $z$ depends on the quantity of pesticides used by farmer $i, \pi_{i}$, the average quantity of pesticides used by the other farmers of crop $z$ in the country, $\bar{\pi}(z)$, and the share of land devoted nationally to the crop, $B(z) \equiv N(z) / N$ where $N(z)$ is the number of crop $z$ plots. ${ }^{10}$ With atomistic individuals ( $N$ is so large that the yield of a single plot has a negligible effect on the market price), the crop $z$ farmer's program can be rewritten as

$$
r(z)=\max _{\pi_{i}} \bar{a}(z) \psi\left(\pi_{i} ; z, \bar{\pi}(z), B(z)\right) \bar{p}(z)-\tau \pi_{i}+T(z)-c,
$$

\footnotetext{
${ }^{9}$ Pests and/or meteorological events do not necessarily totally destroy a plot, but rather affect the quantity of biomass produced. Our assumption allows for tractability, our random variable being the number of harvested plots rather than the share of harvested biomass.

${ }^{10}$ Pesticides have a cross-external positive impact on plots surrounding the area treated because they diminish the overall level of pests. Hence, for a given individual treatment $\pi_{i}(z)$, the larger $\bar{\pi}(z)$, the lower the probability that the plot of farmer $i$ is infected.
} 
where $\bar{p}(z)$ is the per unit average price of crop $z$, defined as (denoting by $\tilde{y}(z)$ the total production level of crop $z$ )

$$
\bar{p}(z) \equiv \frac{\mathrm{E}[\tilde{p}(z) \tilde{y}(z)]}{\mathrm{E}[\tilde{y}(z)]}=p(z)+\frac{\operatorname{cov}(\tilde{p}(z), \tilde{y}(z))}{\mathrm{E}[\tilde{y}(z)]} .
$$

As $\operatorname{cov}(\tilde{p}(z), \tilde{y}(z))<0$, the reference price $\bar{p}(z)$ is lower than the expected market price due to the correlation between total production $\tilde{y}(z)$ and market price $\tilde{p}(z)$. Solving the farmer's program, we obtain that the optimal level of pesticides at the symmetric Nash equilibrium between crop $z$ farmers, $\pi(z)$, satisfies

$$
\psi^{\prime}(\pi(z) ; z, \pi(z), B(z))=\frac{\tau}{\bar{a}(z) \bar{p}(z)}
$$

As the subsidy allows farmers to break even, we have $T(z)=\tau \pi(z) .{ }^{11}$ Competition in the economy leads to $r(z)=0$ for all $z$, hence

$$
\bar{a}(z) \psi(z) \bar{p}(z)=c
$$

where $\psi(z) \equiv \psi(\pi(z) ; z, \pi(z), B(z))$ is the survival probability of a plot of crop $z$ at equilibrium. As plots are identically and independently affected, we obtain that

$$
\mathrm{E}[\tilde{p}(z) \tilde{y}(z)]=\bar{p}(z) \bar{a}(z) \psi(z) N B(z)=c N B(z)
$$

i.e., the expected value of the crop $z$ domestic production is equal to the sum of the wages and the land value involved in its farming.

The survival probability that allows us to derive our results in the following is given by

$$
\psi\left(\pi_{i} ; z, \bar{\pi}, B(z)\right)=\frac{\mu_{0} \exp \left[\pi_{i}\left(\theta(z)-\pi_{i} / 2\right)\right]}{1+\exp \left[(\theta(z)-\bar{\pi})^{2} / 2\right] \kappa(z) B(z)},
$$

where the impact of abiotic factors on the production of crop $z$ is captured by $\mu_{0} \cdot{ }^{12}$ The impact of farmer $i$ 's pesticide use on the resilience of her plot is given by $\exp \left[\pi_{i}(\theta(z)-\right.$ $\left.\pi_{i} / 2\right)$ ], where $\theta(z)$ corresponds to the level of pesticides that maximizes the expected yield of crop $z$. Biodiversity and cross-externality effects appear on the denominator: the expected resilience of individual plots decreases with $B(z)$, the intensity of the crop cultivation, but increases with the average level of pesticides used $\bar{\pi}$, and reaches a maximum at $\bar{\pi}=\theta(z)$. Here, $\kappa(z) \equiv \kappa_{0} \exp \left[-\theta(z)^{2} / 2\right]$ is the lowest crossexternality factor for crop

\footnotetext{
${ }^{11}$ For the sake of simplicity, we consider neither the production nor the market of agrochemicals in the following. Implicitly, farmers thus are "endowed" with a large stock of agrochemicals that farming does not exhaust, leading to prices equal to 0 .

${ }^{12}$ This functional form is derived from a probabilistic model that relies on a beta-binomial probability distribution and represents very robust stylized facts in ecology concerning the parasite-host relationship. For more details, see Bellora et al. (2015).
} 
$z$, when all crop $z$ farmers use pesticide level $\theta(z)$, and $\exp \left[(\theta(z)-\bar{\pi})^{2} / 2\right]$ is the negative effect on the crop's resilience induced by an average use of pesticides $\bar{\pi} \leq \theta(z)$. We assume that $\mu_{0}, \kappa_{0}$ and $\theta(z)$ are the same in both countries and such that $\psi(\cdot) \leq 1{ }^{13}$

Using (2) and (3) we obtain that pesticide use for crop $z$ is given by

$$
\pi(z)=\theta(z)-\tau / c
$$

and that the survival probability of a plot at equilibrium is given by

$$
\psi(z)=\frac{\mu_{0} \exp \left[\theta(z)^{2} / 2\right]}{t[1+t \kappa(z) B(z)]}
$$

where $t \equiv \exp \left[(\tau / c)^{2} / 2\right]=\exp \left[(\theta(z)-\pi(z))^{2} / 2\right]$ is the tax index that measures the negative effect of the restricted use of pesticides on the crop's resilience. This index diminishes with $\pi(z)$ over $[0, \theta(z)]$ and reaches a minimum equal to 1 when $\pi(z)=\theta(z)$ (which corresponds to an absence of regulation, i.e. $\tau=0$ ). Denoting the crop $z$ maximum expected yield as $a(z) \equiv \bar{a}(z) \mu_{0} \exp \left[\theta(z)^{2} / 2\right]$, the crop $z$ reference price is given by

$$
\bar{p}(z)=c t[1+t \kappa(z) B(z)] / a(z)
$$

and the expected domestic production level for crop $z$ by

$$
y(z) \equiv \mathrm{E}[\tilde{y}(z)]=\frac{a(z) N B(z)}{t[1+t \kappa(z) B(z)]}
$$

Production of crop $z$ decreases with $t$ because of two effects: the corresponding reduction in the use of pesticides has a direct negative impact on the productivity of each plot but also an indirect negative cross-externality effect between plots.

\subsection{Demand}

The representative individuals of the two countries share the same preferences over goods. Their preferences are given by the following Cobb-Douglas utility function

$$
U=b \ln x_{I}+(1-b) \int_{0}^{1} \alpha(z) \ln \tilde{x}(z) d z-h Z
$$

where $\int_{0}^{1} \alpha(z) d z=1$ and $h>0$. The first two terms correspond to the utility derived from the consumption of industrial and agricultural goods respectively, while the last term

\footnotetext{
${ }^{13}$ Parameter $\mu_{0}$ may be considered as resulting from factors beyond the control of the collective action of farmers, such as meteorological events, which may differ from one crop to the other and from one country to the other; i.e. we may rather have two functions $\mu(z)$ and $\mu^{*}(z)$ taking different values. However, because competitive advantages are assessed by comparing $a(z)=\mu_{0} \bar{a}(z) \exp \left[\theta(z)^{2} / 2\right]$ to its foreign counterpart, assuming that it is a parameter is innocuous.
} 
corresponds to the disutility of the environmental damages caused by a domestic use of

$$
Z=N \int_{0}^{1} B(z) \pi(z) d z
$$

pesticides by farmers. The demand for the industrial good is $x_{I}=b R$ where $R$ is the revenue per capita. The rest of the revenue, $(1-b) R$, is spent on agricultural goods with individual demand for crop $z$ given by

$$
\tilde{x}(z)=\alpha(z)(1-b) R / \tilde{p}(z)
$$

where $\tilde{p}(z)$ depends on the realized production level $\tilde{y}(z)$ and $\alpha(z)$ is the share of the food spending devoted to crop $z$. We assume that consumers are risk-neutral and thus evaluate their ex ante welfare at the average consumption level of crop $z, x(z) \equiv \mathrm{E}[\tilde{x}(z)]$. Using (9), the corresponding reference price is $\mathrm{E}[1 / \tilde{p}(z)]^{-1}$. At market equilibrium under autarky (the same reasoning applies under free trade), as $L \tilde{x}=\tilde{y}$, we obtain from definition (1) and the fact that $L \tilde{x} \tilde{p}=\alpha(z)(1-b) L R$ that $\bar{p}(z)=\mathrm{E}[1 / \tilde{p}(z)]^{-1}$, i.e. the consumers' and producers' reference prices are the same. The representative consumer's indirect utility function can be written as ${ }^{14}$

$$
V(R, Z)=\ln (R)-(1-b) \int_{0}^{1} \alpha(z) \ln \bar{p}(z) d z-h Z
$$

where $R=(L-N+c N) / L$ since there is no profit at equilibrium.

The government determines the optimal policy by maximizing this utility, taking account of the relationship between pesticides and the value of land.

\subsection{Equilibrium under autarky}

The autarky equilibrium is derived as follows. The market clearing condition for industrial goods allows us to derive the cost of agricultural production $c_{A}$ (the sum of the rental price of the agricultural land and of the wage). ${ }^{15}$ For a given environmental tax level, equilibrium on each crop market gives the sharing of land between crops. These levels allow us to derive the optimal tax policy under autarky.

Due to the constant returns to scale in the industrial sector, the total spending on industrial products must be equal to the total production cost at equilibrium, i.e.,

$$
b L R=b\left(N c_{A}+L-N\right)=L-N
$$

which gives $c_{A}=(\ell-1)(1-b) / b$ where $\ell \equiv L / N>1$. Consequently, the value of land

\footnotetext{
${ }^{14} \mathrm{Up}$ to a constant given by $b \ln (b)+(1-b) \int_{0}^{1} \alpha(z) \ln \alpha(z) d z$.

${ }^{15}$ Subscript "A" indexes equilibrium values under autarky.
} 
is positive if $N<(1-b) L$, a condition assumed to hold in the following. Observe that this value depends neither on the use of pesticides nor on the crops' prices and is the same in both countries in spite of their differences in terms of crop yields. This is due to the Cobb-Douglas preferences (in addition to the constant productivity in the industrial sector).

Market equilibrium on the crop $z$ market implies that total expenses are equal to total production cost, i.e.

$$
\alpha(z)(1-b) L R=N B(z) c_{A}
$$

where the total domestic revenue is given by

$$
L R=N c_{A}+L-N=N(\ell-1) / b
$$

for both countries. Combining these expressions gives that the share of land devoted to crop $z$ satisfies $B(z)=\alpha(z)$. Using (5) and $\tau / c=\sqrt{2 \ln t}$, the disutility of the environmental damages caused by the use of pesticides is given by

$$
Z=N \int_{0}^{1} \alpha(z) \theta(z) d z-N \sqrt{2 \ln t}
$$

The optimal pesticides tax index is determined by maximizing the utility of the representative consumer (10) which reduces to

$$
\min _{t}(1-b) \int_{0}^{1} \alpha(z) \ln \{t[1+t \kappa(z) \alpha(z)]\} d z+h Z
$$

a program that applies to both countries. We obtain that the optimal tax index under autarky, $t_{A}$, solves

$$
\sqrt{2 \ln t_{A}}\left[1+\int_{0}^{1} \frac{t_{A} \kappa(z) \alpha(z)^{2}}{1+t_{A} \kappa(z) \alpha(z)} d z\right]=\frac{N h}{1-b}
$$

As $\kappa(z)=\kappa_{0} \exp \left[-\theta(z)^{2} / 2\right]$, the optimal tax decreases when $\kappa_{0}$ increases, with a maximum given by $\tau_{A}=(L-N) h / b$.

While acreage and pesticide levels are the same in both countries, the average production of each is different because of the differences in crop yields. The revenue being the same in both countries, crop demands are identical but because average production levels are different, break-even prices are also different.

\subsection{Free trade equilibrium}

We show in this section that when Home and Foreign engage in free trade, biodiversity effects result in an incomplete specialisation. Without these effects, productions are 
country-specific as described in Dornbusch et al. (1977), a threshold crop delimiting the production range specific to each country. With biodiversity effects, this clear-cut situation can no longer exist, because specialisation, i.e. the increase in the acreage devoted to a crop, reduces the expected yield. As a result, the two countries share the production of a whole range of crops delimited by two threshold crops. ${ }^{16}$ We detail these results in the next paragraphs.

The free trade equilibrium is derived from the equilibrium on industrial good market which allows us to determine the worldwide agricultural and total revenues. The condition of equalization of total spending with the total production cost on the industrial market is given by

$$
b\left(N c+L-N+N^{*} c^{*}+L^{*}-N^{*}\right)=L-N+L^{*}-N^{*}
$$

where $L=L^{*}$ and $N=N^{*}$. We obtain $c+c^{*}=2(\ell-1)(1-b) / b$, hence that the worldwide agricultural revenue is the same as under autarky. This is also the case for the total revenue, given by

$$
L R+L^{*} R^{*}=N\left[c+c^{*}+2(\ell-1)\right]=2 N(\ell-1) / b .
$$

As under autarky, the share of the agricultural sector of this revenue is unchanged, given by $1-b$. For Home, it results in a per-individual revenue given by

$$
R=\frac{(\ell-1)}{\ell}\left[1+2 q \frac{1-b}{b}\right]
$$

which depends on the fraction $q \equiv c /\left(c+c^{*}\right)$ obtained at equilibrium. This share depends on crop yields and on the environmental tax policies implemented in each country.

However, competitive advantages depend not only on environmental taxes but also on biodiversity effects, i.e. on the way land is farmed. Indeed, for a given tax level, the higher the intensity of the farming of a crop, i.e. the more land is devoted to that crop, the lower the average productivity of the land, because of the production externality effect. In other words, intensification undermines the competitive advantages apparent under autarky. More precisely, if crop $z$ is produced by Home only, the market equilibrium condition implies that worldwide expenses on crop $z$ are equal to total production cost, i.e.,

$$
2 \alpha(z)(\ell-1) N(1-b) / b=N B(z) c
$$

which can be written as $\alpha(z) / q=B(z)$. Opening to trade could thus correspond to a large increase of the acreage devoted to that crop: for example, if $q=1 / 2$, the total farmland

\footnotetext{
${ }^{16}$ Incomplete specialisation is obtained in Dornbusch et al. (1977) considering exogenous trade costs, the so-called Samuelson's iceberg costs. In our setup, it is due to stochastic factors that are directly linked to the production process and evolve with the openness to trade.
} 
doubles which may seriously impair Home's land productivity for crop z. Hence, because of the production externality, it is possible that a whole range of crops is not traded. Crops produced by both countries must satisfy two conditions: on the one hand, the break-even prices for the crops considered are equal in the two countries and, on the other hand, at market equilibrium, worldwide expenditure on crop $z$ is equal to the sum of production costs of the two countries. The first condition (equality of break-even prices), leads to the following equation, using (7):

$$
A(z)=\frac{c^{*}}{c} \frac{t^{*}}{t} \frac{1+t^{*} \kappa(z) B^{*}(z)}{1+t \kappa(z) B(z)}
$$

The second condition (market equilibrium), leads to

$$
2 \alpha(z) N(\ell-1)(1-b) / b=c N B(z)+c^{*} N^{*} B^{*}(z),
$$

which can also be written as

$$
\alpha(z)=q B(z)+q^{*} B^{*}(z)
$$

Crop $z$ is produced by both countries if there exist $B(z)>0$ and $B^{*}(z)>0$ that solve (13) and (14). As stated formally in the following proposition, this is true for a whole range of crops. More precisely,

Proposition 1 Specialization is incomplete under free trade: Assuming $\kappa_{0}$ is not too large, both countries produce crops belonging to $(\underline{z}, \bar{z}), 0 \leq \underline{z}<\bar{z} \leq 1$ satisfying

$$
A(\bar{z})=\frac{t^{*}}{t} \frac{q^{*}+t^{*} \kappa(\bar{z}) \alpha(\bar{z})}{q}
$$

and

$$
A(\underline{z})=\frac{t^{*}}{t} \frac{q^{*}}{q+t \kappa(\underline{z}) \alpha(\underline{z})} .
$$

The intensity of these crops is given by

$$
B(z)=\chi(z) \frac{1-q \phi(z)}{q}
$$

where

$$
\begin{gathered}
\phi(z) \equiv \frac{1+A(z) t / t^{*}}{1+\alpha(z) t^{*} \kappa(z)}, \\
\chi(z) \equiv \frac{1+t^{*} \alpha(z) \kappa(z)}{t \kappa(z)\left[A(z) t / t^{*}+t^{*} / t\right]}
\end{gathered}
$$

for Home and symmetric expressions hold for Foreign (with $A(z)$ replaced by $1 / A(z)$ ). Crops belonging to $[0, \underline{z}]$ are produced by Home only, with intensity $B(z)=\alpha(z) / q$, and 
crops belonging to $[\bar{z}, 1]$ are produced by Foreign only, with intensity $B^{*}(z)=\alpha(z) / q^{*}$.

Proof: see the appendix.

Without any biodiversity effect, i.e. with $\kappa_{0}=0$, using (15) and (16), we end up with $A(\bar{z})=A(\underline{z})=\left(q^{*} / q\right)\left(t^{*} / t\right)$ and thus a unique threshold index and complete specialisation. With biodiversity effects, i.e. with $\kappa_{0}>0$, we have $A(\underline{z})<A(\bar{z})$ and since $A$ is strictly increasing, $\underline{z}<\bar{z}$. For crops ranging between $\underline{z}$ and $\bar{z}$, albeit technical differences exist between the two countries, comparative advantages are trimmed by the negative externality that affects national production of each country.

Using (8) and (17), we obtain that Home's expected production of crop $z \in(\underline{z}, \bar{z})$ is

$$
y_{T}(z)=N a(z) \frac{q^{*}+\alpha(z) \kappa(z) t^{*}-q A(z) t / t^{*}}{t \kappa(z)\left[q t^{*}+q^{*} t+t t^{*} \alpha(z) \kappa(z)\right]} .
$$

Using the symmetric expression for Foreign, we obtain that total expected production under free trade is given by

$$
y_{T}^{W}=N \frac{\alpha(z)\left[a^{*}(z) t_{T} / t_{T}^{*}+a(z) t_{T}^{*} / t_{T}\right]}{q t_{T}^{*}+q^{*} t_{T}+\alpha(z) t_{T} t_{T}^{*} \kappa(z)}
$$

For these crops produced by both countries, the break-even price is

$$
\bar{p}_{m}(z)=\frac{2(1-b)(\ell-1)}{b a(z)} \frac{q\left(t^{*}-t\right)+t\left[1+\alpha(z) t^{*} \kappa(z)\right]}{t^{*} / t+A(z) t / t^{*}} .
$$

For the other crops, the corresponding expected productions and break-even prices are given by

$$
y(z)=\frac{a(z) N \alpha(z)}{t[q+t \kappa(z) \alpha(z)]}
$$

and

$$
\bar{p}_{s}(z)=\frac{2(\ell-1)(1-b) t[q+t \kappa(z) \alpha(z)]}{b a(z)}
$$

for all $z \leq \underline{z}$ and by symmetric expressions for all crops $z \geq \bar{z}$.

From these preliminary results, it is possible to isolate a first effect due to the production externality by supposing that the environmental taxes and the agricultural revenues of the two countries are unchanged at equilibrium.

Lemma 1 Suppose that $t_{T}=t_{T}^{*}=t_{A}$ and $q=1 / 2$ at equilibrium under free trade. Then, the break-even prices of the crops produced by only one country are higher for this country than under autarky and are reduced for the other country. For crops produced by both countries, the price for Home is lower for all crops $z \in\left(A^{-1}(1), \bar{z}\right]$ and larger for all $z \in\left[\underline{z}, A^{-1}(1)\right)$. On the contrary, the price for Foreign is larger for all crops $z \in\left(A^{-1}(1), \bar{z}\right]$ and lower for all $z \in\left[\underline{z}, A^{-1}(1)\right)$. 
Proof: see the appendix.

These increases in break-even prices affecting crops produced more intensively under trade than under autarky are the consequences of the cross-externality effects between plots: while the input prices do not change by assumption, the marginal production cost increases since more pesticides are needed.

Of course, environmental taxes and the sharing of the total agricultural revenue evolve with international trade. Using (5), we obtain that the level of pesticides under free trade is given by

$$
Z_{T}=\frac{N}{q}\left\{\int_{0}^{\underline{z}} \alpha(z) \theta(z) d z+\int_{\underline{z}}^{\bar{z}} \chi(z)[1-q \phi(z)] \theta(z) d z\right\}-N \sqrt{2 \ln t}
$$

which depends on the crops farmed at equilibrium and on how the worldwide agricultural revenue is shared. To determine this share, we can use the fact that the domestic revenues come from the sale of the goods produced nationally. ${ }^{17}$ On interval $[0, \underline{z}]$, all revenues spent are collected by Home, while it is only a share $s(z)$ of them on $[\underline{z}, \bar{z}]$. We thus have

$$
L R=L-N+(1-b)\left(L R+L^{*} R^{*}\right)\left\{\int_{0}^{\underline{z}} \alpha(z) d z+\int_{\underline{z}}^{\bar{z}} s(z) \alpha(z) d z\right\}
$$

which simplifies to

$$
q=\int_{0}^{\underline{z}} \alpha(z) d z+\int_{\underline{z}}^{\bar{z}} s(z) \alpha(z) d z
$$

where $s(z) \equiv y_{T}(z) / y_{T}^{W}(z)$ corresponds to Home's share of expected production relative to the total. Using (4), (14) and (17), we get

$$
s(z)=\frac{q B(z)}{q B(z)+q^{*} B^{*}(z)}=\frac{q B(z)}{\alpha(z)}=\frac{[1-q \phi(z)] \chi(z)}{\alpha(z)}
$$

and thus

$$
q=\frac{\int_{0}^{\underline{z}} \alpha(z) d z+\int_{\underline{z}}^{\bar{z}} \chi(z) d z}{1+\int_{\underline{z}}^{\bar{z}} \phi(z) \chi(z) d z}
$$

\section{Environmental tax policy and trade}

Environmental tax policies determine the sharing of worldwide agricultural revenue and therefore drive the free trade equilibrium. In our setup, taxes on pesticides result from the Nash equilibrium of a two-stage game. In the first stage, Home and Foreign governments choose simultaneously their tax policies. In the second stage farmers decide which crops

\footnotetext{
${ }^{17}$ The same expression can be derived using the equilibrium condition on the land market.
} 
to sow and how much pesticide to use. ${ }^{18}$ Home's government problem when defining its tax policy corresponds to the following program:

$$
\max _{t} \ln (R)-(1-b)\left\{\int_{0}^{\underline{z}} \alpha(z) \ln \bar{p}_{s}(z) d z+\int_{\underline{z}}^{\bar{z}} \alpha(z) \ln \bar{p}_{m}(z) d z+\int_{\bar{z}}^{1} \alpha(z) \ln \bar{p}_{s}^{*}(z) d z\right\}-h Z
$$

where $\bar{p}_{s}^{*}(z)$ is given by (21) with $t$ and $q$ replaced by $t^{*}$ and $q^{*}=1-q$. The optimal environmental policy resulting from this program depends on $t^{*}$ : maximizing (26) gives Home's best-response to Foreign's policy $t^{*}$. Foreign's government is in the symmetric situation, since both governments act simultaneously in a strategic way.

For the sake of argument, we consider two cases in the following. In the first case, governments ignore the relationship between their tax policies and their share of the worldwide agricultural revenue; we call the resulting free trade equilibrium "non-strategic". In the second case, which is more realistic and that we call "strategic trade", governments reckon that the value of land, and thus the total revenue $R$, depends on environmental taxes, $t$ and $t^{*}$. Indeed, one may easily show that the share of world agricultural revenue got by Home, $q$, is negatively related to the domestic environmental tax $t$ and positively related to the foreign environmental tax $t^{*}$. A total differentiation of (23) yields, using $s(\bar{z})=0$ and $s(\underline{z})=1$,

$$
\frac{d q}{d t}=\frac{\int_{\underline{z}}^{\bar{z}}[B(z)(d \chi(z) / d t) / \chi(z)-\chi(z)(d \phi(z) / d t)] d z}{1+\int_{\underline{z}}^{\bar{z}} \phi(z) \chi(z) d z}
$$

where it is straightforward from (19) and (18) that $d \chi(z) / d t<0$ and $d \phi(z) / d t>0$. Hence, we have $d q / d t<0$ and since $q+q^{*}=1-b, d q^{*} / d t=-d q / d t>0$. Because of the strategic substituability of the environmental taxes, pesticides are used more intensively at the strategic trade equilibrium than when governments act non strategically.

To detail this competition effect and assess its interaction with the biodiversity externality that affects production, we consider in the following the case where $\alpha(z)=1$ and $\theta(z)=\theta$ for all $z$ which implies that $\kappa(z)=\kappa_{0} \exp \left(-\theta^{2} / 2\right) \equiv \kappa$ for all $z$. Hence, neither the demand nor the externality on consumers' utility distinguishes crops, and the total use of pesticides simplifies to $Z=N \theta-N \sqrt{2 \ln t}$. We also suppose that $A(z)$ allows us to obtain symmetric equilibria so that $q=1 / 2=z_{s}$ at equilibrium. We analyze the two types of free trade equilibria (non-strategic and strategic) assuming first that there is no biodiversity effect, i.e. $\kappa=0$. In this case, while there are no cross-externality effects between fields of the same crop, farmers still have an incentive to spread pesticides on their plots to increase their expected yield. We then introduce the negative production externality $(\kappa>0)$, which induces decreasing returns to scale in the agricultural sector

\footnotetext{
${ }^{18}$ It is thus a "strategic environmental policy game" as analyzed by Barrett (1994) in an oligopoly setup à la Brander \& Spencer (1985).
} 
at the national level.

\subsection{Trade without biodiversity effect}

Without biodiversity effect, i.e. when $\kappa=0$, the environmental tax under autarky is given by $\tau_{A}=(L-N) h / b$. This result is obtained using $(11),\left(2 \ln t_{A}\right)^{1 / 2}=\tau_{A} / c_{A}$ and $c_{A}=(\ell-1)(1-b) / b$. Under free trade, each country specializes on one segment of the range of crops delimited by threshold $z_{s}$ which satisfies $A\left(z_{s}\right)=\left(q^{*} t^{*}\right) /(q t)$ using (13). Equilibrium on the land market, $\int_{0}^{z_{s}} B(z) d z=\int_{0}^{z_{s}}(1 / q) d z=1$, leads to $q=z_{s}$ : Home's share of the worldwide agricultural revenue is equal to the range of crops produced domestically. Consequently $z_{s}$ solves $\xi\left(z_{s}\right)=t^{*} / t$ where $\xi(z) \equiv A(z) z /(1-z)$ is strictly increasing.

In the non-strategic situation, governments do not take into account the effect of their environmental taxes on the sharing of the agricultural revenue. The effect of the tax policies on $z_{s}, q$ and $R$ are neglected when solving (26). The problem simplifies to

$$
\min _{t}(1-b) q \ln t-h N \sqrt{2 \ln t}
$$

where $q$ is considered as a constant. The first-order condition leads to an optimal tax index that solves

$$
\sqrt{2 \ln t}=\frac{N h}{q(1-b)} .
$$

Using $q=z_{s}$, we get $t=\exp \left\{(N h)^{2}\left[(1-b) z_{s}\right]^{-2} / 2\right\}$ and thus a threshold crop that solves

$$
\xi\left(z_{s}\right)=\exp \left\{\frac{(N h)^{2}\left(1-2 z_{s}\right)}{2\left[(1-b) z_{s}\left(1-z_{s}\right)\right]^{2}}\right\} .
$$

As $\sqrt{2 \ln t}=\tau / c$ and $c=2 q c_{A},(28)$ allows us to obtain $\tau=2 \tau_{A}$ whatever the country's share of the worldwide agricultural revenue. ${ }^{19}$ Stated formally:

Proposition 2 Suppose that there are no biodiversity effects. Then, at the non-strategic trade equilibrium, the environmental tax is doubled compared to under autarky.

The intuition is as follows. The environmental policy affects only crops produced domestically. As the range of domestic products is smaller under free trade than under autarky, the impact of the environmental policy on consumer welfare is reduced on the consumption side (prices affected by the tax are only those produced by Home) while it is unchanged on the environmental side. It is thus optimal to raise the tax compared to under autarky. Trade creates a NIMBY effect: while consumers benefit from the low

\footnotetext{
${ }^{19}$ The fact that the taxes are the same at equilibrium is due to the specifics of our model and the assumption that $\alpha(z)=1$ and $\theta(z)=\theta$ for all $z$, whereas the revenues in the two countries are generally different.
} 
prices allowed by pesticides used abroad, they want pesticide use restricted domestically to reduce pollution. ${ }^{20}$ Observe that the resulting situation is not Pareto optimal: indeed, if the two countries could agree on tax levels, each would have to account for the price effect of its tax on the other country's consumers. In our setup, the resulting Pareto optimal tax level is the autarky one. ${ }^{21}$

Now suppose that governments are strategic in the sense that they take into account the effect of the tax on their shares of agricultural revenue. Using (12) and (26) we obtain that Home's best-response to $t^{*}$ solves

$$
\max _{t, q}\left\{\ln \left(1+\frac{2 q(1-b)}{b}\right)-(1-b)\left[\int_{0}^{q} \ln \bar{p}_{s}(z) d z+\int_{q}^{1} \ln \bar{p}_{s}^{*}(z) d z\right]-h Z: q=\xi^{-1}\left(\frac{t^{*}}{t}\right)\right\}
$$

It is implicitly defined by

$$
\sqrt{2 \ln t}\left\{q+\left[\frac{2}{b+2 q(1-b)}\right] \frac{t^{*}}{t \xi^{\prime}\left(z_{s}\right)}\right\}=\frac{N h}{1-b} .
$$

At a symmetric equilibrium, i.e. $q=1 / 2=z_{s}, t=t^{*}$, which implies that $A(1 / 2)=1$ and thus $\xi^{\prime}\left(z_{s}\right)=A^{\prime}(1 / 2)+4$, we get

$$
\sqrt{2 \ln t}=\frac{N h}{1-b}\left[1+\frac{A^{\prime}(1 / 2)}{A^{\prime}(1 / 2)+8}\right]
$$

The following proposition characterizes the optimal policy at equilibrium:

Proposition 3 Suppose that there are no biodiversity effects. Then, at the symmetric strategic trade equilibrium, the environmental tax $\tau$ verifies $2 \tau_{A}>\tau \geq \tau_{A}$, with $\tau=\tau_{A}$ in the limit case where $A^{\prime}(1 / 2)=0$. Moreover, the steeper the comparative advantage function $A(z)$, the larger the environmental tax.

Proof: see the appendix.

When comparative advantages are not too different, allowing farmers to use more pesticides could have a large impact on the country's market share of agricultural products. At the symmetric equilibrium, countries do not gain market share, but as this rivalry counteracts the NIMBY effect described above, this ineffective competition in terms of market share results in a situation which is a Pareto improvement compared to the non-strategic one.

\footnotetext{
${ }^{20}$ Markusen et al. (1995) and Kennedy (1994) obtain comparable results in an imperfect competition framework. Although under autarky an environmental tax increase is detrimental for consumption, this is not the case when domestic consumers have access to the goods produced in the foreign country. Governments are thus induced to (unilaterally) increase their environmental tax.

${ }^{21}$ Indeed, for any sharing $(q, 1-q)$ of the agricultural revenue $2 c_{A}$, the Pareto optimal tax levels solve $\min _{t} 2(1-b) q \ln t-h N(2 \ln t)^{1 / 2}$ and the equivalent program for Foreign.
} 


\subsection{Biodiversity effects}

Biodiversity effects create two countervailing distortions in the governments' trade-off we have described above. On the one hand, as specialization induced by trade increases the production externality that impedes production, governments should be induced to lower the tax on pesticides with respect to under autarky. On the other hand, as the externality limits specialization, the effect of the tax on prices concerns a reduced set of crops, which should induce governments to increase the tax.

To give a comprehensive appraisal of these countervailing effects, we consider a particular form of the relative potential yield function, given by

$$
A(z)=\frac{1+m(2 z-1)}{1-m(2 z-1)}
$$

where $0<m<1$. We have $0<A(0)<1, A(1)>1, A(1 / 2)=1$ and

$$
A^{\prime}(z)=\frac{4 m}{[1-m(2 z-1)]^{2}}
$$

Hence, the larger $m$, the larger the discrepancy between the countries' relative potential yield away from $z=1 / 2$ (graphically, the relative potential yield curve becomes steeper when $m$ increases). With this particular form, at a symmetric equilibrium, threshold crops given by (15) and (16) simplify to

$$
\bar{z}=\frac{1}{2}+\frac{t \kappa}{2 m(1+t \kappa)}
$$

and

$$
\underline{z}=\frac{1}{2}-\frac{t \kappa}{2 m(1+t \kappa)} .
$$

They are equally distant from the centre of the range of crops $(1 / 2)$, and the length of the subset of crops produced by both countries,

$$
\bar{z}-\underline{z}=\frac{1}{m} \frac{t \kappa}{1+t \kappa},
$$

increases with $\kappa$ and $t$ and decreases with the relative potential yield parameter $m$.

In the non-strategic case, the condition that determines $t$ at the symmetric equilibrium can be written as $(\partial V / \partial t)_{t^{*}=t}=0$ where

$$
\left.\frac{\partial V}{\partial t}\right|_{t^{*}=t}=-\frac{1-b}{t}\left[\frac{1+4 t \kappa}{1+2 t \kappa} \underline{z}+(\bar{z}-\underline{z}) \frac{1+2 t \kappa}{2(1+t \kappa)}\right]-h \frac{d Z}{d t} .
$$

The last term corresponds to the environmental impact of the tax on consumers, which is positive since $d Z / d t<0$. It leads the government to increase the environmental tax. 
The bracketed term is composed of two elements, the first one corresponding to the price effect on the goods produced locally and the second one to the price effect on the goods produced by both countries. In these terms, biodiversity effects are ambiguous. Indeed, using (32) and (33), the effect on goods produced locally can be rewritten as

$$
\frac{1+4 t \kappa}{1+2 t \kappa} \underline{z}=\left(1+\frac{2 t \kappa}{1+2 t \kappa}\right)\left(\frac{1}{2}-\frac{\bar{z}-\underline{z}}{2}\right)
$$

In the first bracket, the fraction $2 t \kappa /(1+2 t \kappa)$ tends to reduce the tax on crops produced locally, compared to the case where $\kappa=0$. The second bracketed term highlights that the range of crops specific to Home is not half of the total but is reduced by $(\bar{z}-\underline{z}) / 2$, which tends to increase the tax. The increase in the range of crops produced by both countries has a second effect, contrary to the one just described, as shown by the term $(\bar{z}-\underline{z})(1+2 t \kappa) /[2(1+t \kappa)]$. However, the effect due to the decrease in the range of specific crops exceeds the one concerning crops produced by both countries. Indeed, we have

$$
\frac{\bar{z}-\underline{z}}{2}\left(1+\frac{2 t \kappa}{1+2 t \kappa}-\frac{1+2 t \kappa}{1+t \kappa}\right)=\frac{\bar{z}-\underline{z}}{2}\left(\frac{2 t \kappa}{1+2 t \kappa}-\frac{t \kappa}{1+t \kappa}\right)>0 .
$$

Hence, in the end, the fact that both countries are producing crops belonging to $(\underline{z}, \bar{z})$ tends to increase the tax level compared to the case where $\kappa=0$. As a result, the environmental tax could be larger or lower than $2 \tau_{A}$, depending on the relative potential yields of crops. More precisely, we have the following result:

Proposition 4 Suppose that the relative potential yield function is given by (30). Then, at the symmetric non-strategic trade equilibrium, biodiversity effects result in a reduction of the environmental tax compared to the case where $\kappa=0$ unless $m$ is very small. Overall, the environmental tax is greater than under autarky.

Proof: see the appendix.

When the discrepancy in relative potential yields is large between the two countries, specialization is important (the range of crops produced by both is relatively small), and the cross externality effect is optimally contained by an intensive use of pesticides.

In the strategic case, there is a marginal effect of the environmental tax on the share of the agricultural revenue that induces governments to reduce their environmental tax. Indeed, the marginal effect of the tax policy on welfare is given by

$$
\frac{d V}{d t}=\frac{\partial V}{\partial t}+\frac{\partial V}{\partial q} \frac{d q}{d t}
$$

which entails an additional term compared to the non-strategic case, where

$$
\frac{\partial V}{\partial q}=\frac{2(1-b)}{b+2 q(1-b)}-(1-b)\left[\frac{\underline{z}}{q+t \kappa}-\frac{1-\bar{z}}{1-q+t^{*} \kappa}+\frac{(\bar{z}-\underline{z})\left(t^{*}-t\right)}{q\left(t^{*}-t\right)+t\left(1+t^{*} \kappa\right)}\right] .
$$


The first term corresponds to the direct effect on welfare due to the increase in revenue while the remaining terms concern the effects on the price of crops produced domestically, abroad and by both countries respectively. At a symmetric equilibrium, the price effects cancel out, leading to $(\partial V / \partial q)_{t^{*}=t, q=1 / 2}=2(1-b)$. Using (30), we obtain that $(27)$ is expressed as

$$
\left.\frac{d q}{d t}\right|_{t^{*}=t, q=1 / 2}=-\frac{3+9 t \kappa+4(t \kappa)^{2}}{12 t(1+t \kappa)[m(1+t \kappa)+1]}
$$

which decreases with $\kappa$. The greater the biodiversity effects, the stronger the negative impact of the environmental tax on the share of the agricultural revenue. However, notwithstanding the marginal effect of the tax on the revenue, we show in the appendix the following result

Proposition 5 Suppose that the relative potential yield function is given by (30). Then, at the symmetric strategic trade equilibrium the environmental tax is generally greater than under autarky.

Proof: see the appendix.

To sum up, the main effects linking trade and the pesticide policy are the following: when governments neglect the impact of the tax on the terms of trade (i.e. under non strategic trade) and without biodiversity effects, the NIMBY effects described in section 3.1 drive the increase in taxes. Still under non strategic trade but with biodiversity effects, the production externality leads to a decrease in the taxes, counteracting the NIMBY effect. However, the tax remains higher than under autarky. In the strategic case, the marginal effect of the environmental tax on the market share leads governments to soften their environmental policy. Nevertheless, the environmental policy remains more stringent under free trade than under autarky.

\section{Trade and volatility}

Agricultural production is affected both by the way land is farmed, which depends on the specialization induced by trade, and by the public regulation on pesticides. This section is devoted to the impacts of these elements on the volatility of the productions and of the prices.

\subsection{Production volatility}

We compare the volatility of crop production between the autarky and the free trade situations using the variation coefficient (VC), defined for random variable $\tilde{X}$ as $v(\tilde{X}) \equiv$ 
$\sigma(\tilde{X}) / \mathrm{E}(\tilde{X})$. As plots are independently affected by pests, the variance of crop $z$ domestic production is given by $\operatorname{Var}(\tilde{y}(z))=\bar{a}(z)^{2} N B(z) \psi(z)[1-\psi(z)] .^{22}$ Denoting $\mu(z) \equiv$ $\mu_{0} \exp \left(\theta(z)^{2} / 2\right)$ and using (6) and (8), the variation coefficient for the production by Home of a crop $z$ is given by

$$
v(\tilde{y}(z))=\left\{\frac{t[1+t \kappa(z) B(z)]-\mu(z)}{\mu(z) N B(z)}\right\}^{1 / 2} .
$$

This coefficient increases with the tax index $t$ and the intensity of biodiversity effects $\kappa$, while it decreases with the total number of plots $N$ and the share of the agricultural area dedicated to the considered crop, $B$. Due to independence, both the variance and the mean increase linearly with $N$, which results in a negative "scale" effect on volatility: the larger the agricultural area of the country, the lower the variation coefficient. There is also a scale effect associated to intensification (an increase in $B$ ) that dominates biodiversity effects. The variation coefficients of the worldwide production of crop $z$ under autarky are given by

$$
v\left(\tilde{y}_{A}^{W}(z)\right)=\frac{\left[\operatorname{Var}\left(\tilde{y}_{A}(z)\right)+\operatorname{Var}\left(\tilde{y}_{A}^{*}(z)\right)\right]^{1 / 2}}{\tilde{y}_{A}(z)+\tilde{y}_{A}^{*}(z)}=\frac{\left\{\left[\bar{a}(z)^{2}+\bar{a}^{*}(z)^{2}\right] N \alpha(z) \psi(z)[1-\psi(z)]\right\}^{1 / 2}}{\left[\bar{a}(z)+\bar{a}^{*}(z)\right] N \alpha(z) \psi(z)} .
$$

Using (6), we get

$$
v\left(\tilde{y}_{A}^{W}(z)\right)=\left\{1-\frac{2 A(z)}{[1+A(z)]^{2}}\right\}^{1 / 2}\left\{\frac{t_{A}\left[1+t_{A} \kappa(z) \alpha(z)\right]-\mu(z)}{\mu(z) N \alpha(z)}\right\}^{1 / 2} .
$$

While the second bracketed term in (38) is similar to (37), the first term reveals a yield effect on production volatility when the same crops are produced by both countries: as $A(z) /[1+A(z)]^{2}$ is cap-shaped with a maximum at $A(z)=1$, this effect is decreasing for $z<1 / 2$ and increasing for $z>1 / 2$. Hence, the yield effect on volatility is higher the larger the difference between the crop yields of the two countries. ${ }^{23}$

Assuming symmetry, $\alpha(z)=1$ and $\theta(z)=\theta$ (which implies $\mu(z)=\mu$ and $\kappa(z)=\kappa$ for all $z$ ), the volatility of domestic production is the same for all crops under autarky and for all crops produced by one country only under free trade. Indeed, in these two cases, the intensification effects are constant, since, under autarky, $B(z)=1$ for all $z$ and, under free trade, $B(z)=2$ for all crops in the range $\left[0 ; \underline{z}\right.$ [ and $B^{*}(z)=2$ for all crops in the range $] \bar{z} ; 1]$. But the effects of intensification on volatility vary from one crop to

\footnotetext{
${ }^{22}$ This variance is obtained considering that plots survive to pests following a binomial distribution of parameters $N B(z)$, the number of plots growing crop $z$, and $\psi(z)$, the survival probability of each of these plots. Denoting this variable $\tilde{X}(z)$, we have $\tilde{y}(z)=\bar{a}(z) \tilde{X}(z)$ and thus $\operatorname{Var}(\tilde{y}(z))=\bar{a}(z)^{2} \operatorname{Var}(\tilde{X}(z))$, with $\operatorname{Var}(\tilde{X}(z))=N B(z) \psi(z)[1-\psi(z)]$.

${ }^{23}$ With identical yields, i.e. $A(z)=1$, this term is equal to $\sqrt{2} / 2$, the scale effect of a doubling of farmland.
} 
the other when we consider crops produced by both countries $(z \in[\underline{z} ; \bar{z}])$ since farmland intensities vary. The total share of land devoted to crops at the symmetric equilibrium is the same $\left(B(z)+B^{*}(z)=2\right.$ in any case), but the relative importance of Home is decreasing with $z$ (from $B(\underline{z})=2$ to $B(\bar{z})=0$ ), whereas it is constant under autarky. To compute the volatility of the world production of crops produced by both countries we use $\operatorname{Var}\left(\tilde{y}^{W}(z)\right)=\operatorname{Var}\left(\tilde{y}_{T}(z)\right)+\operatorname{Var}\left(\tilde{y}_{T}^{*}(z)\right)$ and $v\left(\tilde{y}^{W}(z)\right)^{2}=s(z)^{2} v(\tilde{y}(z))^{2}+s^{*}(z)^{2} v\left(\tilde{y}^{*}(z)\right)^{2}$, which lead to

$$
v\left(\tilde{y}^{W}(z)\right)=\left\{\frac{(1+t \kappa)(1+2 t \kappa)-\mu \kappa}{2 \mu N \kappa}-\frac{2(1+t \kappa)^{2}}{\mu N \kappa} \frac{A(z)}{[1+A(z)]^{2}}\right\}^{1 / 2} .
$$

As under autarky, there is a yield effect at work: the volatility index is decreasing over $[\underline{z}, 1 / 2)$, increasing over $(1 / 2, \bar{z}]$, and thus reaches a minimum at $z=1 / 2$. Comparing the VCs under autarky and trade, we obtain the following result:

Proposition 6 Without biodiversity effects, trade could potentially reduce the production volatility of all crops. However, because of a higher environmental tax than under autarky only the volatility of crops for which countries have large comparative advantages is reduced (if any). With biodiversity effects, trade increases the production volatility of crops produced by both countries and of the specialized crops with moderate competitive advantage. The volatility of large comparative advantage crops is reduced only if biodiversity effects are small and the environmental tax not too different from its autarky level.

Proof: see the appendix.

\subsection{Price volatility}

Some characteristics of the prices distributions can be derived from the properties of the production distributions. We take advantage from the fact that the survival probability of a given plot, $\psi$, does not depend on the total number of plots $N$, and thus that the distribution of the number of plots that survive converges to a normal distribution when $N$ is large. This implies that the distribution of crop $z$ production converges to the normal distribution $\mathcal{N}(y(z), \sigma(\tilde{y}(z)))$. First, observe that the break-even price $\bar{p}(z)$ corresponds to crop $z$ median price: we have $\operatorname{Pr}[\tilde{p}(z) \leq \bar{p}(z)]=\operatorname{Pr}[\tilde{y}(z) \geq y(z)]=1 / 2$ since the normal distribution is symmetric. Consequently, as $\bar{p}(z)$ is lower than the average market price $p(z)$ due to the correlation between prices and quantities, the price distribution is asymmetric.

This asymmetry is also revealed by the upper and lower bounds of the confidence intervals of crop prices, which are implied by the distribution of crop production. Denoting by $y_{d}^{\gamma}(z)$ and $y_{u}^{\gamma}(z)$ the lower and upper bounds of the confidence interval of the production of crop $z$ at confidence level $1-\gamma$, the corresponding price bounds are derived from 
$L \tilde{x}=\tilde{y}$ and (9), which give $\operatorname{Pr}\left[y_{d}^{\gamma}(z) \leq \tilde{y}(z) \leq y_{u}^{\gamma}(z)\right]=\operatorname{Pr}\left[p_{d}^{\gamma}(z) \leq \tilde{p}(z) \leq p_{u}^{\gamma}(z)\right]$ where $p_{u}^{\gamma}(z) \equiv \alpha(z)(1-b) L R / y_{d}^{\gamma}(z)$ and $p_{d}^{\gamma}(z) \equiv \alpha(z)(1-b) L R / y_{u}^{\gamma}(z)$. Because production distributions are symmetric, $y_{d}^{\gamma}(z)$ and $y_{u}^{\gamma}(z)$ are equally distant from $y(z)$. However, since prices and quantities are inversely related, this is not the case for $p_{d}^{\gamma}(z)$ and $p_{u}^{\gamma}(z)$. The following proposition completes these general features of the price distributions with some useful approximations.

Proposition 7 The expected value and the standard deviation of crop prices are approximated by

$$
p(z) \approx \bar{p}(z)\left[1+v(\tilde{y}(z))^{2}\right]
$$

and

$$
\sigma(\tilde{p}(z)) \approx \bar{p}(z) v(\tilde{y}(z)) \sqrt{1-v(\tilde{y}(z))^{2}}
$$

Confidence intervals at confidence level $1-\gamma$ are delimited by $p_{u}^{\gamma}(z)=p(z)+s_{u}^{\gamma} \sigma(\tilde{p}(z))$ and $p_{d}^{\gamma}(z)=p(z)+s_{d}^{\gamma} \sigma(\tilde{p}(z))$ with

$$
s_{u}^{\gamma} \approx \frac{v(\tilde{y}(z))+s_{\gamma}}{\left[1-s_{\gamma} v(\tilde{y}(z))\right]\left[1-v(\tilde{y}(z))^{2}\right]^{1 / 2}}
$$

and

$$
s_{d}^{\gamma} \approx \frac{v(\tilde{y}(z))-s_{\gamma}}{\left[1+s_{\gamma} v(\tilde{y}(z))\right]\left[1-v(\tilde{y}(z))^{2}\right]^{1 / 2}}
$$

where $s_{\gamma} \equiv \Phi^{-1}(1-\gamma / 2)$, $\Phi$ being the cumulative distribution function of the standard normal distribution. Bounds of the confidence interval of the price of crop z are approximately equal to

$$
p_{u}^{\gamma}(z) \approx \bar{p}(z)\left[1+v(\tilde{y}(z))^{2}+v(\tilde{y}(z)) \frac{v(\tilde{y}(z))+s_{\gamma}}{1-s_{\gamma} v(\tilde{y}(z))}\right]
$$

and

$$
p_{d}^{\gamma}(z) \approx \bar{p}(z)\left[1+v(\tilde{y}(z))^{2}+v(\tilde{y}(z)) \frac{v(\tilde{y}(z))-s_{\gamma}}{1+s_{\gamma} v(\tilde{y}(z))}\right]
$$

Proof: see the appendix.

Because prices and quantities are inversely related, we have $s_{d}<s_{u}$, i.e the price distribution is skewed to the right: its right tail is longer and fatter than its left tail. The consequences on volatility are that the chances that a crop price is very low compared to the expected price, i.e., $\tilde{p}(z) \leq \bar{p}(z)<p(z)$, are larger than the chances of a high price, i.e. $\tilde{p}(z)>p(z)$, since $1 / 2=\operatorname{Pr}[\tilde{p}(z) \geq \bar{p}(z)]>\operatorname{Pr}[\tilde{p}(z)>p(z)]$. However, the possible range of high prices is wider than the range of low prices: $p_{u}(z)-p(z)>p(z)-p_{d}(z)>\bar{p}(z)-p_{d}(z)$. Note nevertheless that this result depends on the convexity of the demand function. ${ }^{24}$

\footnotetext{
${ }^{24}$ The condition $p_{u}(z)-p(z)>p(z)-p_{d}(z)$ is equivalently written $p(z)<\left[p_{u}(z)+p_{d}(z)\right] / 2$, with
} 


\subsection{Illustration}

Figures 1 and 2 illustrate these findings. The solid curves with the marks depict the crop average price in each case as indicated (depicted are Home's autarky prices). The corresponding dashed curves depict the approximate values of $p_{d}(z)$ and $p_{u}(z)$. The vertical distance between these curves corresponds to a confidence interval at level equal to $95 \%$. Compared to under autarky, the non-strategic average prices are larger for almost all crops, and the confidence intervals are very large. This is due to the tightening of the pesticide regulations mentioned above. The strategic effects that loosen these regulations induce lower average prices and confidence intervals. Biodiversity effects are reflected in Fig. 2 by strategic and non-strategic average price curves that encompass a flat portion around $z=1 / 2$ which corresponds to the mix-production range. Confidence intervals over these ranges are smaller the closer the crop is to $z=1 / 2$.

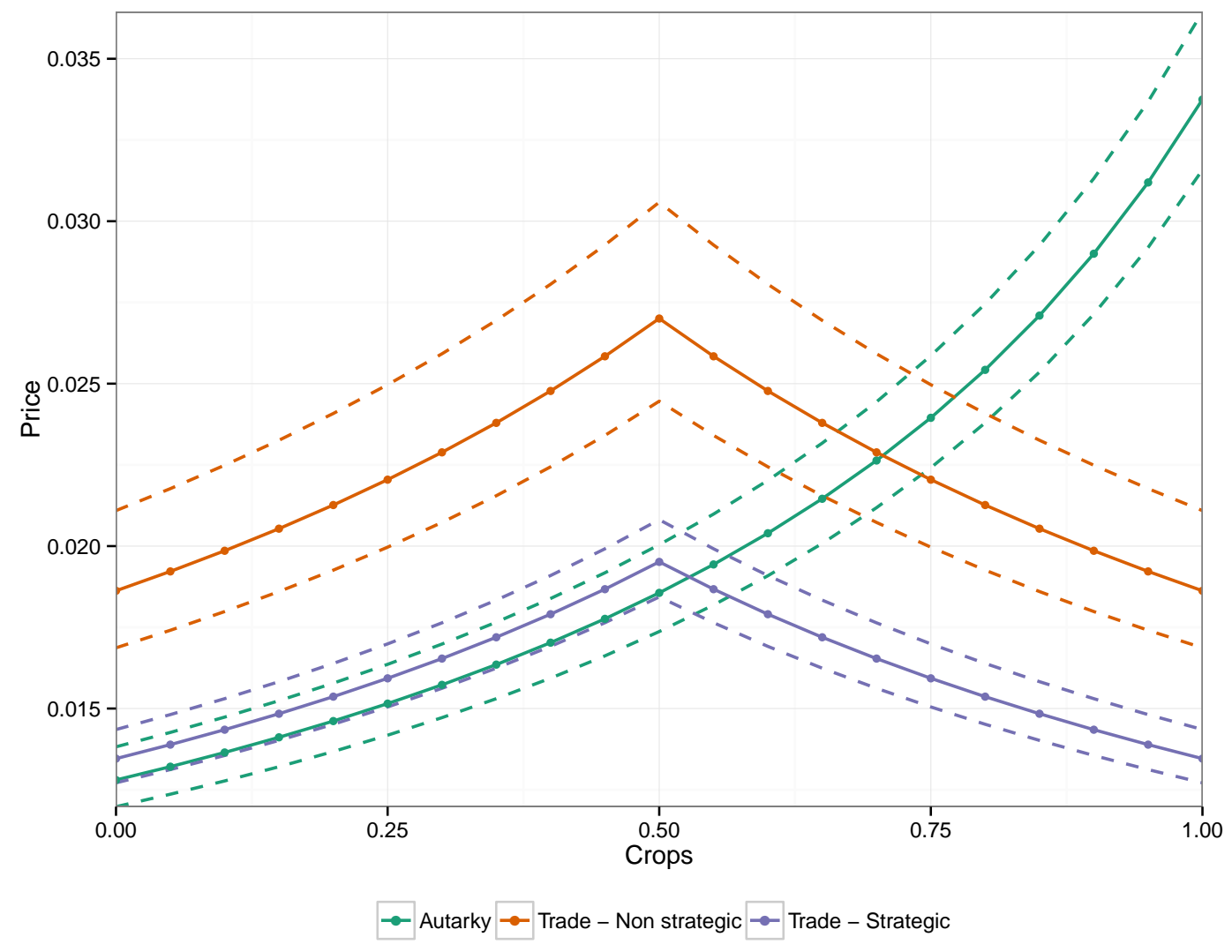

Figure 1: Average prices and price volatility (confidence interval at $95 \%$ confidence level) without biodiversity effects. $\kappa=0, N=100, h=10^{-3}, b=0.8, \ell=20, m=0.45, \mu=1, a(1 / 2)=29$.

Tables 1 and 2 assess the way the biodiversity effects and potential yield differentials affect the trade pattern, the environmental tax policy, the food price average level and $\left.\left.\overline{\left[p_{u}(z)+p_{d}(z)\right] / 2=\left[D^{-1}\left(y_{d}(z)\right)+D^{-1}\left(y_{u}\right.\right.}(z)\right)\right] / 2$, where $D$ is the demand function. As $p(z)>\bar{p}(z)=$ $D^{-1}(y(z))$ where $y(z)=\left[y_{d}(z)+y_{u}(z)\right] / 2$, a necessary condition is $D^{-1}\left(\left[y_{d}(z)+y_{u}(z)\right] / 2\right) \leq\left[D^{-1}\left(y_{d}(z)\right)+\right.$ $\left.D^{-1}\left(y_{u}(z)\right)\right] / 2$, hence $D^{-1}(y)$ must be convex from the Jensen's inequality. 


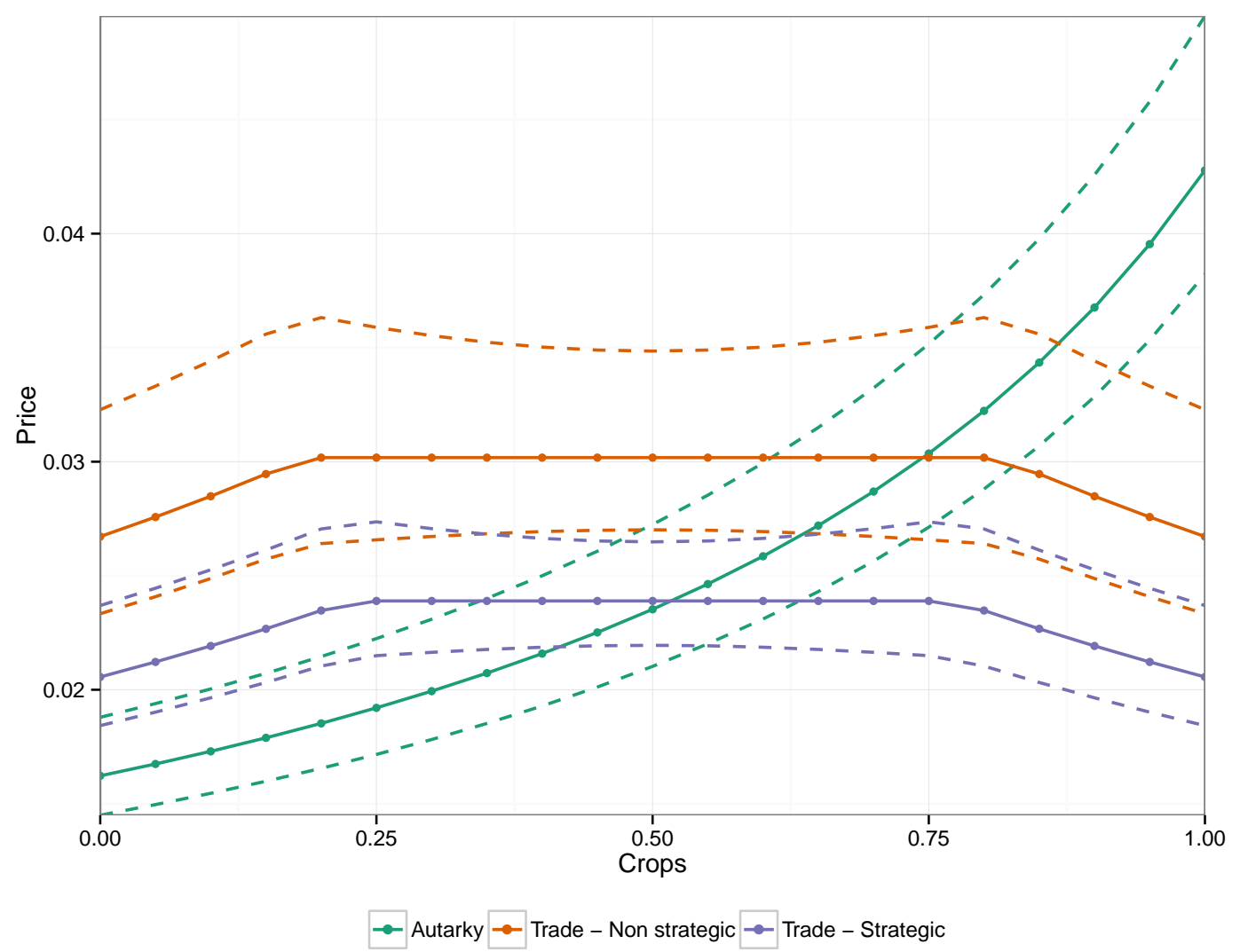

Figure 2: Average prices and price volatility (confidence interval at $95 \%$ confidence level) with biodiversity effects. $\kappa=0.3, N=100, h=10^{-3}, b=0.8, \ell=20, m=0.45, \mu=1, a(1 / 2)=29$.

the crop price volatilities. ${ }^{25}$ Table 1 summarizes the impacts due to the biodiversity effects: the larger $\kappa$ is, the larger the negative impact of the cultivation intensity on the survival probability of plots. Biodiversity effects play against the specialization induced by trade: the range of crops produced by both countries increases when $\kappa$ rises. Since biodiversity effects impede production, prices increase with $\kappa$ as shown by the trend in the food price index reported in table 1 . The larger $\kappa$ is, the more effective pesticides are in reducing the negative externality due to the cultivation intensity and, therefore, the lower the environmental tax. Nevertheless, pesticides do not allow farmers to eradicate the biodiversity effect. Thus, even if more pesticides are applied when $\kappa$ increases, the food price volatility increases. The tax on pesticides is more stringent under trade than under autarky, even when trade is strategic, for the reasons detailed above. In our simulations,

\footnotetext{
${ }^{25}$ The tables report the tax as a percentage of production costs $\tau / c(c$ is the same whatever the case at hand). The food price index is defined as $\int_{0}^{1} p(z) y(z) d z / \int_{0}^{1} y(z) d z$ and approximated as detailed in the appendix. A food price index of 2 means that the average price of agricultural goods equals $2 \%$ of the industrial goods price. The variation coefficient of domestic crop prices is the same for all crops under autarky. Worldwide variation coefficients indicated under autarky are derived from a fictitious price distribution corresponding to the sum of Home and Foreign productions. Worldwide variation coefficients evolve between minimum value $v\left(\tilde{p}^{W}(1 / 2)\right)$ and maximum values $v\left(\tilde{p}^{W}(0)\right)$ (autarky) and $v\left(\tilde{p}^{W}(\underline{z})\right)$ (trade).
} 
Table 1: Sensitivity analysis on parameter $\kappa$

\begin{tabular}{lrrrrr}
\hline & \multicolumn{5}{c}{ Values of $\kappa$} \\
\cline { 2 - 6 } Variables (\%) & 0.1 & 0.3 & 0.5 & 0.7 & 0.9 \\
\hline Autarky & & & & & \\
$\tau / c$ & 45.46 & 40.15 & 37.07 & 35.05 & 33.61 \\
$\quad$ Food price index & 2.03 & 2.38 & 2.73 & 3.09 & 3.45 \\
$v(\tilde{p}(\cdot))$ & 8.62 & 10.10 & 11.39 & 12.53 & 13.57 \\
$v\left(\tilde{p}^{W}(1 / 2)\right)$ & 5.46 & 6.29 & 6.99 & 7.60 & 8.14 \\
$v\left(\tilde{p}^{W}(0)\right)$ & 6.24 & 7.16 & 7.94 & 8.61 & 9.20 \\
Non strategic trade & & & & & \\
$\tau / c$ & 83.29 & 73.23 & 69.03 & 66.49 & 64.68 \\
Food price index & 2.28 & 2.83 & 3.35 & 3.85 & 4.32 \\
$v\left(\tilde{p}^{W}(1 / 2)\right)$ & 8.00 & 8.84 & 9.76 & 10.62 & 11.42 \\
$v\left(\tilde{p}^{W}(\underline{z})\right)$ & 8.82 & 10.61 & 12.19 & 13.55 & 14.75 \\
$\bar{z}-\underline{z}$ & 20.66 & 46.96 & 64.70 & 77.69 & 87.65 \\
Strategic trade & & & & & \\
$\tau / c$ & 52.51 & 44.83 & 40.99 & 38.53 & 36.76 \\
Food price index & 1.77 & 2.25 & 2.68 & 3.08 & 3.46 \\
$v\left(\tilde{p}^{W}(1 / 2)\right)$ & 6.39 & 7.37 & 8.28 & 9.10 & 9.85 \\
$v\left(\tilde{p}^{W}(\underline{z})\right)$ & 7.07 & 8.91 & 10.42 & 11.70 & 12.84 \\
$\bar{z}-\underline{z}$ & 17.16 & 41.51 & 58.71 & 71.64 & 81.76 \\
\hline$m=0.6, N=100, h=10^{-3}, b=0.8, \ell=20, \mu=0.7, a(1 / 2)=290$.
\end{tabular}

non strategic taxes are more than $58 \%$ higher than strategic ones. Food price index levels reported in table 1 show that the decrease in food prices due to trade is lower the larger the biodiversity effects. The ratio between the $\mathrm{VC}$ levels at $z=1 / 2$ of the worldwide production and the domestic production under autarky gives the size of the scale effect on prices (e.g. for $\kappa=0.1$, it corresponds to $5.46 / 8.62=63.3 \%$ which is lower than on the production side $\sqrt{2} / 2 \approx 70.7 \%$ ). The yield effect is maximum for crop $z=0$ : for $\kappa=0.1$, it corresponds to an additional (6.24-5.46)/8.62=9\%. Table 1 also illustrates that the price volatility increases for crops produced by both countries even for small values of $\kappa$ because of the significant increases in the environmental tax under strategic trade compared to under autarky: even for $\kappa=0.1$, the volatility of the specialized crops $(7.07 \%)$ is larger than under autarky $(6.24 \%)$.

Table 2 describes the impact of the potential crop yield differentials: the larger $m$ is, the larger the difference in the potential yield of each crop (away from $z=1 / 2$ ), and the greater the difference in comparative advantages of the two countries. The range of crops that are produced by both countries under free trade $(\bar{z}-\underline{z})$ decreases with $m$. Effects of $m$ on the environmental tax depend on whether trade is strategic or not. Under non strategic trade, the impact of the environmental policy on consumer welfare goes through the crop prices only. Therefore, the larger $m$ is, the larger the specialization and 
Table 2: Sensitivity analysis on parameter $m$

\begin{tabular}{lrrrr}
\hline & \multicolumn{4}{c}{ Values of $m$} \\
\cline { 2 - 5 } Variables $(\%)$ & 0.2 & 0.4 & 0.6 & 0.8 \\
\hline Autarky & 45.46 & 45.46 & 45.46 & 45.46 \\
$\tau / c$ & 2.03 & 2.03 & 2.03 & 2.03 \\
Food price index & 8.62 & 8.62 & 8.62 & 8.62 \\
$v(\tilde{p}(\cdot))$ & 5.46 & 5.46 & 5.46 & 5.46 \\
$v\left(\tilde{p}^{W}(1 / 2)\right)$ & 5.55 & 5.83 & 6.24 & 6.76 \\
$v\left(\tilde{p}^{W}(0)\right)$ & & & & \\
Non strategic trade & 86.02 & 83.94 & 83.29 & 82.97 \\
$\tau / c$ & 2.70 & 2.47 & 2.28 & 2.12 \\
Food price index & 8.19 & 8.05 & 8.00 & 7.98 \\
$v\left(\tilde{p}^{W}(1 / 2)\right)$ & 9.02 & 8.87 & 8.82 & 8.80 \\
$v\left(\tilde{p}^{W}(\underline{z})\right)$ & 63.23 & 31.13 & 20.66 & 15.46 \\
$\bar{z}-\underline{z}$ & & & & \\
Strategic trade & 46.82 & 49.83 & 52.51 & 54.81 \\
$\tau / c$ & 2.00 & 1.88 & 1.77 & 1.68 \\
Food price index & 6.18 & 6.29 & 6.39 & 6.49 \\
$v\left(\tilde{p}^{W}(1 / 2)\right)$ & 6.84 & 6.96 & 7.07 & 7.17 \\
$v\left(\tilde{p}^{W}(\underline{z})\right)$ & 50.19 & 25.43 & 17.16 & 13.01 \\
$\bar{z}-\underline{z}$ & & & & \\
& & & & \\
$\kappa=0.1, N=100, h=10^{-3}, b=0.8, \ell=20, \mu=0.7, a(1 / 2)$ & $=290$.
\end{tabular}

the lower the tax on pesticides. Under strategic trade, the use of pesticides may have a significant impact on the market share of the country, particularly when comparative advantages are sufficiently close. This is reflected in table 2: the smaller $m$ is, the lower the environmental tax. The way the food price index varies with $m$ also differs between the non strategic and the strategic case. Two effects play on the quantities produced: on the one hand, when $m$ raises, the productivity increases and, on the other hand, when the environmental tax increases, the quantities produced decrease. In the non strategic case, when $m$ increases, the tax decreases. Then, the two effects go in the same direction, the quantities produced increase and prices decline. Under strategic trade, $m$ and the environmental tax both increase, their effects are countervailing on the quantities produced. The impact of the increase in the productivity prevails and the food price index decreases, even if the environmental tax is raised. Finally, in both strategic and non strategic cases, price volatility increases when the use of pesticides declines, i.e. when the environmental tax raises. 


\section{Conclusion}

We have shown that biotic risk factors such as pests that affect the productivity of farming create biodiversity effects that modify standard results of trade models. An explicit account of their effects on production allows us to clarify the distribution of idiosyncratic risks affecting farming which depends on the countries' openness to trade. These production shocks translate into the price distribution and are impacted by environmental policies. Of course, these productive shocks are not the only ones affecting food prices, but they are an additional factor in their distributions that may explain their greater volatility compared to manufacture prices.

While these effects are analytically apparent within the standard two-country Ricardian model, an extension to a more encompassing setup involving a larger number of countries as permitted by Eaton \& Kortum (2002) and applied to agricultural trade by Costinot \& Donaldson (2012) and Costinot et al. (2012) is necessary to investigate their scope statistically. These studies incorporate a stochastic component to determine the pattern of trade but it is not related to the production process and somehow arbitrary. Our analysis offers an interesting route to ground these approaches at least in the case of agricultural products. Introducing these biodiversity effects should allow for a better assessment of the importance of trade costs in determining the pattern of trade. 


\section{References}

Barrett, S. (1994). Strategic environmental policy and intrenational trade. Journal of Public Economics, 54(3), 325 - 338.

Beketov, M. A., Kefford, B. J., Schafer, R. B., \& Liess, M. (2013). Pesticides reduce regional biodiversity of stream invertebrates. Proceedings of the National Academy of Sciences, 110(27), 11039-11043.

Bellora, C., Blanc, E., Bourgeon, J.-M., \& Strob, E. (2015). Estimating the impact of crop diversity on agricultural productivity in South Africa. Working paper.

Brander, J. A. \& Spencer, B. J. (1985). Export subsidies and international market share rivalry. Journal of International Economics, 18(1-2), 83-100.

Costinot, A. \& Donaldson, D. (2012). Ricardo's theory of comparative advantage: Old idea, new evidence. American Economic Review, 102(3), 453-58.

Costinot, A., Donaldson, D., \& Komunjer, I. (2012). What goods do countries trade? a quantitative exploration of ricardo's ideas. The Review of Economic Studies, 79(2), 581-608.

Di Falco, S. (2012). On the value of agricultural biodiversity. Annual Review of Resource Economics, 4(1), $207-223$.

Di Falco, S. \& Chavas, J. (2006). Crop genetic diversity, farm productivity and the management of environmental risk in rainfed agriculture. European Review of Agricultural Economics, 33(3), 289-314.

Di Falco, S. \& Perrings, C. (2005). Crop biodiversity, risk management and the implications of agricultural assistance. Ecological Economics, 55(4), 459-466.

Dornbusch, R., Fischer, S., \& Samuelson, P. A. (1977). Comparative advantage, trade, and payments in a ricardian model with a continuum of goods. The American Economic Review, 67(5), pp. 823-839.

Drakare, S., Lennon, J. J., \& Hillebrand, H. (2006). The imprint of the geographical, evolutionary and ecological context on species-area relationships. Ecology Letters, 9(2), $215-227$.

Eaton, J. \& Kortum, S. (2002). Technology, geography, and trade. Econometrica, 70(5), 1741-1779.

EC (2009). EU Action on pesticides "Our food has become greener". Technical report, European Commission.

ECP (2013). Industry statistics. Technical report, European Crop Protection.

EEA (2010). 10 messages for 2010 - Agricultural ecosystems. Technical report, European Environment Agency. 
Fernandez-Cornejo, J., Jans, S., \& Smith, M. (1998). Issues in the economics of pesticide use in agriculture: a review of the empirical evidence. Review of Agricultural Economics, 20(2), 462-488.

Gaisford, J. \& Ivus, O. (2014). Should smaller countries be more protectionist ? the diversification motive for tariffs. Review of International Economics, 22(4), 845-862.

Garcia Martin, H. \& Goldenfeld, N. (2006). On the origin and robustness of power-law species-area relationships in ecology. Proceedings of the National Academy of Sciences, 103(27), 10310-10315.

Gilbert, C. L. \& Morgan, C. W. (2010). Food price volatility. Philosophical Transactions of the Royal Society B: Biological Sciences, 365(1554), 3023-3034.

Jacks, D. S., O'Rourke, K. H., \& Williamson, J. G. (2011). Commodity price volatility and world market integration since 1700. Review of Economics and Statistics, 93(3), 800-813.

Jiguet, F., Devictor, V., Julliard, R., \& Couvet, D. (2012). French citizens monitoring ordinary birds provide tools for conservation and ecological sciences. Acta Oecologica, $44(0), 58-66$.

Kennedy, P. W. (1994). Equilibrium pollution taxes in open economies with imperfect competition. Journal of Environmental Economics and Management, 27(1), 49 - 63.

Markusen, J. R., Morey, E. R., \& Olewiler, N. (1995). Competition in regional environmental policies when plant locations are endogenous. Journal of Public Economics, $56(1), 55-77$.

May, R. M. (2000). Species-area relations in tropical forests. Science, 290(5499), 20842086.

Newbery, D. M. G. \& Stiglitz, J. E. (1984). Pareto inferior trade. The Review of Economic Studies, 51(1), pp. 1-12.

Oerke, E. (2006). Crop losses to pests. Journal of Agricultural Science, 144(1), 31.

Pianka, E. R. (2011). Evolutionary Ecology. E-book.

Pimentel, D. (2005). Environmental and economic costs of the application of pesticides primarily in the United States. Environment, Development and Sustainability.

Plotkin, J. B., Potts, M. D., Yu, D. W., Bunyavejchewin, S., Condit, R., Foster, R., Hubbell, S., LaFrankie, J., Manokaran, N., Lee, H.-S., \& et al. (2000). Predicting species diversity in tropical forests. Proceedings of the National Academy of Sciences, 97(20), 10850-10854.

Savary, S., Willocquet, L., Elazegui, F. A., Castilla, N. P., \& Teng, P. S. (2000). Rice pest constraints in tropical asia: Quantification of yield losses due to rice pests in a range of production situations. Plant Disease, 84(3), 357-369. 
Smale, M., Hartell, J., Heisey, P. W., \& Senauer, B. (1998). The contribution of genetic resources and diversity to wheat production in the Punjab of Pakistan. American Journal of Agricultural Economics, 80(3), 482-493.

Stewart, W. M., Dibb, D. W., Johnston, A. E., \& Smyth, T. J. (2005). The contribution of commercial fertilizer nutrients to food production. Agronomy Journal, 97(1), 1.

Storch, D., Keil, P., \& Jetz, W. (2012). Universal species - area and endemics - area relationships at continental scales. Nature, 488(7409), 78-81.

Sutton, M., Howard, C., Erisman, J., Billen, G., Bleeker, A., Grennfelt, P., Grinsven, v. H., \& Grizzetti, B., Eds. (2011a). The European Nitrogen Assessment: Sources, Effects and Policy Perspectives. Cambridge University Press.

Sutton, M. A., Oenema, O., Erisman, J. W., Leip, A., van Grinsven, H., \& Winiwarter, W. (2011b). Too much of a good thing. Nature, 472(7342), 159-161.

Tilman, D. \& Downing, J. A. (1994). Biodiversity and stability in grasslands. Nature, 367(6461), 363-365.

Tilman, D., Polasky, S., \& Lehman, C. (2005). Diversity, productivity and temporal stability in the economies of humans and nature. Journal of Environmental Economics and Management, 49(3), 405-426.

Tilman, D., Wedin, D., \& Knops, J. (1996). Productivity and sustainability influenced by biodiversity in grassland ecosystems. Nature, 379(6567), 718-720.

Turnovsky, S. J. (1974). Technological and price uncertainty in a ricardian model of international trade. The Review of Economic Studies, 41(2), 201.

Weitzman, M. L. (2000). Economic profitability versus ecological entropy. The Quarterly Journal of Economics, 115(1), pp. 237-263.

Wright, B. D. (2011). The economics of grain price volatility. Applied Economic Perspectives and Policy, 33(1), 32-58. 


\section{Appendix}

\section{A Proof of Proposition 1}

For given $t, t^{*}, c, c^{*},(13)$ and (14) define a system of two linear equations with two unknowns. Solving this system gives (17). By definition of threshold crops $\underline{z}$ and $\bar{z}$, we must have $B(z)=0$ for all $z \geq \bar{z}$ and $B^{*}(z)=0$ for all $z \leq \underline{z}$. This implies that we must have $\phi(z) \geq 1 / q$ or all $z \geq \bar{z}$ and $\phi^{*}(z) \geq 1 / q^{*}$ for all $z \leq \underline{z}$. Differentiating (18) and its counterpart for Foreign, we get

$$
\dot{\phi}(z) \equiv \frac{\phi^{\prime}(z)}{\phi(z)}=\frac{A^{\prime}(z)}{t^{*} / t+A(z)}-t^{*} \kappa_{0} e^{-\theta(z)^{2} / 2} \frac{\alpha^{\prime}(z)-\theta^{\prime}(z) \alpha(z)}{1+t^{*} \alpha(z) \kappa(z)}
$$

and

$$
\dot{\phi}^{*}(z)=-\dot{A}(z)+\frac{A^{\prime}(z)}{t^{*} / t+A(z)}-t \kappa_{0} e^{-\theta(z)^{2} / 2} \frac{\alpha^{\prime}(z)-\theta^{\prime}(z) \alpha(z)}{1+t^{*} \alpha(z) \kappa(z)} .
$$

Suppose $\kappa_{0}=0$ : As $\dot{A}(z)>0$, we have $\dot{\phi}(z)=A^{\prime}(z) /\left[t^{*} / t+A(z)\right]>0$ and $\dot{\phi}^{*}(z)=$ $-\dot{A}(z)\left(t^{*} / t\right) /\left[t^{*} / t+A(z)\right]<0$. Both conditions are thus satisfied if $\kappa_{0}$ is sufficiently small. They are also satisfied whatever the value of $\kappa_{0}$ if $\alpha(z)$ and $\theta(z)$ are constant as supposed in the symmetric case considered in section 3. Eq. (15) and (16) are derived from $\phi(\bar{z})=1 / q$ and $\phi^{*}(\underline{z})=1 / q^{*}$ respectively. Using these equations, we obtain $A(\bar{z}) / A(\underline{z})=$ $\left[q^{*}+t^{*} \kappa(\bar{z}) \alpha(\bar{z})\right][q+t \kappa(\underline{z}) \alpha(\underline{z})] /\left(q q^{*}\right)>1$. As $A(z)$ is increasing, we thus have $\bar{z}>\underline{z}$.

\section{B Proof of Lemma 1}

Consider the crops produced more intensively by Home (symmetric results hold for Foreign). For all $z<\underline{z}$, it is obvious by setting $t=t_{A}$ and $q=1 / 2$ in $(21)$ that $\bar{p}(z)>\bar{p}_{A}(z)$ given by $(7)$ where $c=(\ell-1)(1-b) / b$ and $B(z)=\alpha(z)$. For Foreign, we have $\bar{p}(z)<\bar{p}_{A}^{*}(z)$ iff

$$
\frac{1+t_{A} \kappa(z) \alpha(z)}{1+2 t_{A} \kappa(z) \alpha(z)}>A(z)
$$

As $\phi^{*}(z)>1 / q^{*}$ for all $z<\underline{z}$, we obtain by setting $t=t_{A}$ and $q^{*}=1 / 2$ that

$$
\frac{1+1 / A(z)}{1+t_{A} \kappa(z) \alpha(z)}>2
$$

for all $z<\underline{z}$, which gives, re-arranging terms

$$
A(z)<\frac{1}{1+2 t_{A} \kappa(z) \alpha(z)}<\frac{1+t_{A} \kappa(z) \alpha(z)}{1+2 t_{A} \kappa(z) \alpha(z)}
$$

hence $\bar{p}(z)<\bar{p}_{A}^{*}(z)$ for all $z<\underline{z}$. For crops $z$ in $[\underline{z}, \bar{z}]$, we obtain using $(20)$ that $\bar{p}(z)<$ 
$\bar{p}_{A}(z)$ iff $2 /[1+A(z)]<1$, hence the result.

\section{Proof of Proposition 3}

Using (21) which simplifies to

$$
\bar{p}_{s}(z)=\frac{2(\ell-1)(1-b) t q}{b a(z)}
$$

and denoting by $\varpi$ the Lagrange multiplier associated with the constraint, the first-order condition with respect to $t$ gives

$$
-(1-b) q+\frac{N h}{\sqrt{2 \ln t}}-\varpi \frac{1}{\xi^{\prime}\left(z_{s}\right)} \frac{t^{*}}{t}=0
$$

and the one with respect to $q$

$$
\varpi=\frac{2(1-b)}{b+2 q(1-b)} .
$$

Plugging the latter expression into the former and rearranging terms gives (29). At a symmetric equilibrium, using $\xi^{\prime}\left(z_{s}\right)=A^{\prime}(1 / 2)+4$ and $\tau_{A} / c_{A}=N h /(1-b)$, we get

$$
\frac{\tau}{c}=\frac{\tau_{A}}{c_{A}}\left[1+\frac{A^{\prime}(1 / 2)}{A^{\prime}(1 / 2)+8}\right]
$$

where $c=c_{A}$. We thus have

$$
\tau=\tau_{A}\left[1+\frac{A^{\prime}(1 / 2)}{A^{\prime}(1 / 2)+8}\right]
$$

Denoting $M \equiv A^{\prime}(1 / 2)$, we get $\lim _{M \rightarrow 0} \tau=\tau_{A}, \lim _{M \rightarrow+\infty} \tau=2 \tau_{A}$ and

$$
\frac{d \tau}{d M}=\frac{8 \tau_{A}}{(M+8)^{2}}>0
$$

\section{Proof of Proposition 4}

Differentiating (26) with respect to $t$, we obtain the following FOC

$$
\frac{\partial V}{\partial t}=-(1-b)\left[\underline{z} \frac{q+2 t \kappa}{t(q+t \kappa)}+\frac{(\bar{z}-\underline{z})\left(q^{*}+t^{*} \kappa\right)}{q\left(t^{*}-t\right)+t\left(1+t^{*} \kappa\right)}-\int_{\underline{z}}^{\bar{z}} \frac{A(z) / t^{*}-t^{*} / t^{2}}{A(z) t / t^{*}+t^{*} / t} d z\right]-h \frac{d Z}{d t} .
$$


At a symmetric equilibrium, using $(A(z)-1) /(A(z)+1)=m(2 z-1)$ and integrating gives (34). Using (33) in (34) and collecting terms, we arrive at

$$
\frac{\partial V}{\partial t}=\frac{N h}{t \sqrt{2 \ln t}}-(1-b)\left[\frac{1}{2 t}+\kappa \frac{2 m(1+t \kappa)^{2}-t \kappa}{2 m(1+2 t \kappa)(1+t \kappa)^{2}}\right] .
$$

Denote by $t_{0}$ the optimal tax when there is no cross-externality effects, i.e. $\kappa=0$. It verifies (28) where $q=1 / 2$. We have

$$
\left.\frac{\partial V}{\partial t}\right|_{t=t_{0}}=-(1-b) \kappa \frac{2 m\left(1+t_{0} \kappa\right)^{2}-t_{0} \kappa}{2 m\left(1+2 t_{0} \kappa\right)\left(1+t_{0} \kappa\right)^{2}}
$$

which is positive if

$$
m \leq \frac{t_{0} \kappa}{2\left(1+t_{0} \kappa\right)^{2}} \leq 1 / 8
$$

We also have

$$
\begin{aligned}
\left.\frac{1}{1-b} \frac{\partial V}{\partial t}\right|_{t=t_{A}} & =\frac{1}{2 t_{A}}+\frac{\kappa}{1+t_{A} \kappa}-\kappa \frac{2 m\left(1+t_{A} \kappa\right)^{2}-t_{A} \kappa}{2 m\left(1+2 t_{A} \kappa\right)\left(1+t_{A} \kappa\right)^{2}} \\
& =\frac{1}{2 t_{A}}+\frac{t_{A} \kappa^{2}}{1+t_{A} \kappa} \frac{2 m\left(1+t_{A} \kappa\right)+1}{2 m\left(1+2 t_{A} \kappa\right)\left(1+t_{A} \kappa\right)}>0
\end{aligned}
$$

hence $t>t_{A}$ at the optimum.

\section{E Proof of Proposition 5}

At a symmetric equilibrium (35) simplifies to

$$
\frac{\partial V}{\partial q}=2(1-b)+2(1-b) \frac{1-(\bar{z}+\underline{z})}{1+2 t \kappa}
$$

where $\bar{z}+\underline{z}=1$, hence $\partial V / \partial q=2(1-b)$. We also obtain using $(27)$ that at a symmetric equilibrium

$$
\frac{d q}{d t}=-\frac{\frac{2(1+t \kappa)}{t} \int_{\underline{z}}^{\bar{z}} \frac{A(z)}{[A(z)+1]^{2}} d z-\frac{1}{2 t} \int_{\underline{z}}^{\bar{z}} \frac{A(z)}{A(z)+1} d z}{t \kappa+\bar{z}-\underline{z}} .
$$

Denoting $m_{0}=(m+1) / 2$, using

$$
\begin{aligned}
\int_{\underline{z}}^{\bar{z}} \frac{A(z)}{[A(z)+1]^{2}} d z & =\int_{\underline{z}}^{\bar{z}}\left[m_{0}-m z-\left(m_{0}-m z\right)^{2}\right] d z \\
& =(\bar{z}-\underline{z})\left(m_{0}-m / 2\right)+\frac{\left(m_{0}-m \bar{z}\right)^{3}-\left(m_{0}-m \underline{z}\right)^{3}}{3 m} \\
& =\frac{t \kappa}{2 m(1+t \kappa)} \frac{2(1+t \kappa)^{2}+1+2 t \kappa}{6(1+t \kappa)^{2}}
\end{aligned}
$$


and

$$
\int_{\underline{z}}^{\bar{z}} \frac{A(z)}{A(z)+1} d z=\int_{\underline{z}}^{\bar{z}}\left(1-m_{0}+m z\right) d z=(\bar{z}-\underline{z})\left(1-m_{0}+m / 2\right)=\frac{t \kappa}{2 m(1+t \kappa)}
$$

yields (36). Differentiating, we get

$$
\frac{d q^{2}}{d t d \kappa}=-\frac{(4-m)(1+t \kappa)^{2}+4 m(1+t \kappa)+2}{12(1+t \kappa)^{2}[m(1+t \kappa)+1]^{2}}<0
$$

Using (45) we obtain

$$
\left.\frac{1}{1-b} \frac{d V}{d t}\right|_{t=t_{A}}=\frac{1}{2 t_{A}}+\frac{t_{A} \kappa^{2}\left[2 m\left(1+t_{A} \kappa\right)+1\right]}{2 m\left(1+2 t_{A} \kappa\right)\left(1+t_{A} \kappa\right)^{2}}-\frac{3+9 t_{A} \kappa+4\left(t_{A} \kappa\right)^{2}}{6 t_{A}\left(1+t_{A} \kappa\right)\left[m\left(1+t_{A} \kappa\right)+1\right]}
$$

where the second term diverges when $m$ tends to 0 and decreases with $m$ while the last term increases with $m$ (decreases in absolute value). Assuming that $m$ is large enough and $\kappa \approx 0$, we have

$$
\begin{aligned}
\left.\frac{1}{1-b} \frac{d V}{d t}\right|_{t=t_{A}} & =\frac{1}{2 t_{A}}-\frac{1+3 t_{A} \kappa}{2 t_{A}\left[m\left(1+2 t_{A} \kappa\right)+1+t_{A} \kappa\right]}+o(\kappa) \\
& =\frac{1}{2 t_{A}}\left[\frac{m\left(1+2 t_{A} \kappa\right)-2 t_{A} \kappa}{m\left(1+2 t_{A} \kappa\right)+\left(1+t_{A} \kappa\right)}\right]+o(\kappa)
\end{aligned}
$$

where the bracketed term is negative if

$$
m<\bar{m} \equiv \frac{2 t_{A} \kappa}{1+2 t_{A} \kappa} .
$$

However, as the second term of (46) diverges when $m$ approaches 0 , we cannot neglect this term unless $m$ is above some threshold $\underline{m}>t_{A} \kappa /\left(1+t_{A} \kappa\right)$. Indeed, in the case where $m=t_{A} \kappa /\left(1+t_{A} \kappa\right)$, we have

$$
\begin{aligned}
\left.\frac{1}{1-b} \frac{d V}{d t}\right|_{t=t_{A}} & =\frac{1}{2 t_{A}}+\frac{\kappa}{2\left(1+t_{A} \kappa\right)}-\frac{3+9 t_{A} \kappa+4\left(t_{A} \kappa\right)^{2}}{6 t_{A}\left(1+t_{A} \kappa\right)^{2}} \\
& =\frac{\left(t_{A} \kappa\right)^{2}}{3 t_{A}\left(1+t_{A} \kappa\right)^{2}}>0 .
\end{aligned}
$$

Hence, assuming $\kappa$ is small enough, cases where the environmental tax at equilibrium is lower than under autarky correspond to $m \in[\underline{m}, \bar{m}]$ where

$$
\bar{m}-\underline{m}<\frac{2 t_{A} \kappa}{1+2 t_{A} \kappa}-\frac{t_{A} \kappa}{1+t_{A} \kappa}=\frac{t_{A} \kappa}{\left(1+t_{A} \kappa\right)\left(1+2 t_{A} \kappa\right)} \leq \frac{\sqrt{2}}{4+3 \sqrt{2}} \approx 0.17
$$




\section{F Proof of Proposition 6}

Without biodiversity effects, using (37) and (38) with $\kappa=0$, we obtain that $v\left(\tilde{y}_{A}^{W}(z)\right) \geq$ $v\left(\tilde{y}^{W}(z)\right)$ iff

$$
1-\frac{4 A(z)}{[1+A(z)]^{2}} \geq \frac{t-t_{A}}{t_{A}-\mu}
$$

As $A(z) /[1+A(z)]^{2}$ is cap-shaped with a maximum equal to $1 / 4$ at $z=1 / 2$, this condition is satisfied for all $z$ only if $t=t_{A}$. With $t>t_{A}$, it could be satisfied for $z$ belonging only to one of the extremes of the crops' range, i.e. for $z$ either close to 0 or close to 1 , if $t-t_{A}$ is small enough. With biodiversity effects, for $z \in[\underline{z}, \bar{z}]$, using (39) and assuming that $t \geq t_{A}$, we obtain that $v\left(\tilde{y}_{A}^{W}(z)\right) \geq v\left(\tilde{y}^{W}(z)\right)$ iff

$$
\frac{4 A(z)}{[1+A(z)]^{2}}-1 \geq \frac{t \kappa(1+t \kappa)-\kappa t_{A}\left(1+t_{A} \kappa\right)}{(1+t \kappa)^{2}-\kappa t_{A}\left(1+t_{A} \kappa\right)+\mu \kappa}
$$

which is impossible unless $t=t_{A}$ and $z=1 / 2$ since the last term is positive. For all $z \in[0, \underline{z}] \cup[\bar{z}, 1]$, using $(37)$, we have $v\left(\tilde{y}_{A}^{W}(z)\right) \geq v\left(\tilde{y}^{W}(z)\right)$ iff

$$
2-\frac{4 A(z)}{[1+A(z)]^{2}} \geq \frac{t(1+2 t \kappa)-\mu}{t_{A}\left(1+t_{A} \kappa\right)-\mu}
$$

A necessary condition is given by $2>[t(1+2 t \kappa)-\mu] /\left[t_{A}\left(1+t_{A} \kappa\right)-\mu\right]$, or re-arranging terms $t_{A}-\mu>\left(t-t_{A}\right)\left[1+2 \kappa\left(t+t_{A}\right)\right]$ which is satisfied only if $t-t_{A}$ is not too large and $\kappa$ sufficiently small.

\section{G $\quad$ Proof of Proposition 7}

A second-order approximation gives

$$
\begin{aligned}
\tilde{p}(z) & =\frac{\alpha(z)(1-b) L R}{\tilde{y}(z)} \approx \frac{\alpha(z)(1-b) L R}{y(z)}\left[1-\frac{\tilde{y}(z)-y(z)}{y(z)}+\left(\frac{\tilde{y}(z)-y(z)}{y(z)}\right)^{2}\right] \\
& =\bar{p}(z)\left[2-\frac{\tilde{y}(z)}{y(z)}+\left(\frac{\tilde{y}(z)-y(z)}{y(z)}\right)^{2}\right]
\end{aligned}
$$

and thus

$$
p(z) \approx \bar{p}(z)\left[1+E\left(\frac{\tilde{y}(z)-y(z)}{y(z)}\right)^{2}\right]=\bar{p}(z)\left[1+v(\tilde{y}(z))^{2}\right] .
$$

A first order approximation yields

$$
\frac{E\left[(\tilde{p}(z)-\bar{p}(z))^{2}\right]^{1 / 2}}{\bar{p}(z)} \approx E\left[\left(1-\frac{\tilde{y}(z)}{y(z)}\right)^{2}\right]^{1 / 2}=v(\tilde{y}(z)),
$$


which gives

$$
\begin{aligned}
\sigma(\tilde{p}(z)) & \approx E\left[\tilde{p}(z)-\bar{p}(z)-\bar{p}(z) v(\tilde{y}(z))^{2}\right]^{1 / 2}=\left(E\left[(\tilde{p}(z)-\bar{p}(z))^{2}\right]-\bar{p}(z)^{2} v(\tilde{y}(z))^{4}\right)^{1 / 2} \\
& =\bar{p}(z) v(\tilde{y}(z))\left(1-v(\tilde{y}(z))^{2}\right)^{1 / 2}
\end{aligned}
$$

From $p_{u}^{\gamma}(z)=p(z)+s_{u}^{\gamma} \sigma(\tilde{p}(z))$ we get

$$
\begin{aligned}
s_{u}^{\gamma} & \approx \frac{1}{\sigma(\tilde{p}(z))}\left(\frac{\alpha(z)(1-b) L R}{y(z)-s_{\gamma} \sigma(\tilde{y}(z))}-\bar{p}(z)\left(1+v(\tilde{y}(z))^{2}\right)\right) \\
& =\frac{\bar{p}(z)}{\sigma(\tilde{p}(z))} \frac{y(z)\left(1+v(\tilde{y}(z))^{2}\right)-y(z)+s_{\gamma} \sigma(\tilde{y}(z))}{y(z)-s_{\gamma} \sigma(\tilde{y}(z))} \\
& \approx \frac{y(z) v(\tilde{y}(z))^{2}+s_{\gamma} \sigma(\tilde{y}(z))}{v(\tilde{y}(z))\left(1-v(\tilde{y}(z))^{2}\right)^{1 / 2}\left(y(z)-s_{\gamma} \sigma(\tilde{y}(z))\right)} \\
& =\frac{v(\tilde{y}(z))+s_{\gamma}}{\left(1-v(\tilde{y}(z))^{2}\right)^{1 / 2}\left(1-s_{\gamma} v(\tilde{y}(z))\right)}
\end{aligned}
$$

which gives (43). Similar derivations for $p_{d}^{\gamma}(z)=E[\tilde{p}(z)]-s_{d}^{\gamma} \sigma(\tilde{p}(z))$ yield (42) and (44).

\section{H Food Price Index}

The food price index is defined as

$$
F=\int_{0}^{1} y(z) p(z) d z / \int_{0}^{1} y(z) d z
$$

where $p(z)$ is approximated by (40). As we also have $\bar{p}(z) y(z)=c N B(z)$, we get $p(z) y(z) \approx c N B(z)\left[1+v(\tilde{y}(z))^{2}\right]$. In autarky, $c=(\ell-1)(1-b) / b$. Using $B(z)=1$, $\theta(z)=\theta$, which implies $\mu(z)=\mu$, and $y(z)=a(z) N /[t(1+t \kappa)]$ gives

$$
\int_{0}^{1} p(z) y(z) d z=\frac{N(\ell-1)(1-b)}{b}\left[1+\frac{t(1+t \kappa)-\mu}{N \mu}\right] .
$$

Using $a(z)=\mu_{0} e^{\theta^{2} / 2}[1-m(2 z-1)]$ yields

$$
\int_{0}^{1} y(z) d z=\frac{N}{t(1+t \kappa)} \int_{0}^{1} \mu_{0} e^{\theta^{2} / 2}[1-m(2 z-1)] d z=\frac{N \mu_{0} e^{\theta^{2} / 2}}{t(1+t \kappa)}
$$

and thus

$$
F_{A}=\frac{(\ell-1)(1-b) t(1+t \kappa)}{b \mu_{0} e^{\theta^{2} / 2}}\left[1+\frac{t(1+t \kappa)-\mu}{N \mu}\right] .
$$

Under free trade, we have $\bar{p}(z) y(z)=2 N(l-1)(1-b) / b . B(z)=2$ for crops produced 
by only one country and we get, using $\underline{z}+\bar{z}=1$,

$$
\int_{0}^{\underline{z}} p_{s}(z) y(z) d z+\int_{\bar{z}}^{1} p_{s}(z) y^{*}(z) d z=\frac{4 \underline{z} N(l-1)(1-b)}{b}\left[1+\frac{t(1+2 t \kappa)-\mu}{2 \mu N}\right] .
$$

For crops produced by both countries we obtain

$$
\begin{aligned}
& \int_{\underline{z}}^{\bar{z}} p_{m}(z) y_{W}(z) d z=\int_{\underline{z}}^{\bar{z}} \frac{2 N(\ell-1)(1-b)}{b}\left[1+\frac{(1+t \kappa)(1+2 t \kappa)-\mu \kappa}{2 \mu N \kappa}-\frac{2(1+t \kappa)^{2}}{\mu N \kappa} \frac{A(z)}{[1+A(z)]^{2}}\right] d z \\
= & \frac{2 N(\ell-1)(1-b)}{b}\left\{\left[1+\frac{(1+t \kappa)(1+2 t \kappa)-\mu \kappa}{2 \mu N \kappa}\right](\bar{z}-\underline{z})-\frac{t\left[2(1+t \kappa)^{2}+1+2 t \kappa\right]}{\mu N m 6(1+t \kappa)}\right\} .
\end{aligned}
$$

The corresponding quantities are given by

$$
\begin{aligned}
\int_{0}^{\underline{z}} y(z) d z+\int_{\bar{z}}^{1} y(z) d z & =\frac{2 N}{t(1+2 t \kappa)}\left\{\int_{0}^{\underline{z}} a(z) d z+\int_{\bar{z}}^{1} a^{*}(z) d z\right\} \\
& =\frac{2 N \mu_{0} e^{\theta^{2} / 2}}{t(1+2 t \kappa)}[\underline{z}(m+1-m \underline{z})+1-\bar{z}(1+m \bar{z}-m)]
\end{aligned}
$$

and

$$
\int_{\underline{z}}^{\bar{z}} y_{W}(z) d z=\frac{N}{t(1+t \kappa)} \int_{\underline{z}}^{\bar{z}}\left[a^{*}(z)+a(z)\right] d z=\frac{2 N \mu_{0} e^{\theta^{2} / 2}(\bar{z}-\underline{z})}{t(1+t \kappa)}=\frac{2 N \mu_{0} e^{\theta^{2} / 2} \kappa}{m(1+t \kappa)^{2}} .
$$

\section{Fertilizers}

Our focus being on biodiversity effects in agricultural production, we have so far not discussed the impact of trade on the use of fertilizers. However, because they have considerable effects on both crop yields and on the environment (and human health), changes in the openness of countries to trade are likely to impact the way their use is regulated. ${ }^{26}$ We may thus expect that crop price volatility is also affected through this channel. It is possible to analyze these changes by considering that crop $z$ 's potential yield $\bar{a}(z)$ is the result of the intrinsic quality of land and the quantity of fertilizers spread on the field, $g(z)$. Denoting by $a_{0}(z)$ the potential crop $z$ yield absent any treatment, we have $\bar{a}(z)=a_{0}(z) f(g(z))$ with $f(0)=1, f^{\prime}(g)>0$ and $f^{\prime \prime}(g)<0$. Total use of fertilizers, given by $G=N \int_{0}^{1} B(z) g(z) d z$, has a negative impact on consumer welfare due to environmental damages. As pesticides, fertilizers have a direct positive impact on crop yields,

\footnotetext{
${ }^{26}$ Commercial fertilizers are responsible for $30 \%$ to $50 \%$ of crop yields (Stewart et al., 2005). Sutton et al. (2011a,b) find that half of the nitrogen added to farm fields ends up polluting water or air. Excess of nitrogen and phosphorus in freshwater increases cancer risk and creates aquatic and marine dead zones through eutrophication. In the air, nitrates contribute to ozone generation which causes respiratory and cardiovascular diseases. Sutton et al. (2011a) estimates that in the European Union the benefits of nitrogen for agriculture through the increase in yields amount to 25 to 130 billion euros per year and that they cause between 70 and 320 billion euros per year in damage.
} 
but unlike pesticides, their productive impact is limited to the field they are spread on. Hence, the trade-off that defines the fertilizer policy is similar to the one of the pesticide regulation without biodiversity effects. While under autarky domestic consumers bear all the costs and reap all the benefits of the fertilizers used by their fellow farmers, this is no longer the case in free trade: they benefit from the crops produced abroad and share the advantages of a productive national sector with foreign consumers. As a result, restrictions on fertilizers are tighter under free trade than under autarky, with the same caveat as for pesticides: governments may use the fertilizer policy strategically. How lenient they are depends on the impact of fertilizers on relative yields: the more responsive is the relative yields function, i.e. the larger $f^{\prime}(g)$, the lower the restrictions. 